\title{
Early and Persistent Abnormal Decoding by Glial Cells at the Neuromuscular Junction in an ALS Model
}

\author{
Danielle Arbour, ${ }^{1,2}$ Elsa Tremblay, ${ }^{1,2}$ Éric Martineau, ${ }^{1,2}$ Jean-Pierre Julien, ${ }^{3}$ and Richard Robitaille ${ }^{1,2}$ \\ ${ }^{1}$ Département de neurosciences, Université de Montréal, Montréal, Québec H3C 3J7, Canada, ${ }^{2}$ Groupe de recherche sur le système nerveux central, \\ Université de Montréal, Station centre-ville, Montréal, Québec H3C 3J7, Canada, and 32Département de psychiatrie et de neurosciences, Université Laval, \\ Québec G1V 0A6, Canada
}

\begin{abstract}
Amyotrophic lateral sclerosis (ALS) is a late-onset neuromuscular disease characterized by progressive loss of motor neurons (MNs) preceded by neuromuscular junction (NMJ) denervation. Despite the importance of NMJ denervation in ALS, the mechanisms involved remain unexplored and ill defined. The contribution of glial cells in the disease has been highlighted, including axonal Schwann cell activation that precedes the decline of motor function and the onset of hindlimb paralysis. Because NMJ denervation occurs early in the process and that perisynaptic Schwann cells (PSCs), glial cells at the NMJ, regulate morphological stability, integrity, and repair of the NMJ, one could predict that PSC functions would be altered even before denervation, contributing to NMJ malfunctions. We tested this possibility using a slowly progressive model of ALS (SOD1 ${ }^{G 3 R}$ mice). We observed a normal NMJ organization at a presymptomatic stage of ALS (120 d), but PSC detection of endogenous synaptic activity revealed by intracellular $\mathrm{Ca}^{2+}$ changes was enhanced compared with their wild-type littermates. This inappropriate PSC decoding ability was associated with an increased level of neurotransmitter release and dependent on intrinsic glial properties related to enhanced muscarinic receptor activation. The alteration of PSC muscarinic receptor functions also persists during the preonset stage of the disease and became dependent on MN vulnerability with age. Together, these results suggest that PSC properties are altered in the disease process in a manner that would be detrimental for NMJ repair. The impairments of PSC functions may contribute to NMJ dysfunction and ALS pathogenesis.
\end{abstract}

Key words: motor unit properties; muscarinic receptors; perisynaptic Schwann cells; SOD1; synaptic transmission

\section{Introduction}

Amyotrophic lateral sclerosis (ALS) is a neurodegenerative disease characterized by the progressive loss of upper and lower motor neurons (MNs). One of the primary pathogenic events that occur in ALS is the denervation and destruction of neuromuscular junctions (NMJs) (Frey et al., 2000; Fischer et al., 2004; Pun et al., 2006; Dupuis and Loeffler, 2009). An important distinction has been shown whereby fast-fatigable MNs are known to be affected first, whereas the slow-type MNs are partially resistant, purportedly attempting to reinnervate previously denervated muscle fibers (Frey et al., 2000; Atkin et al., 2005; Schaefer et al., 2005; Pun et al., 2006; Hegedus et al., 2007, 2008).

Received April 2, 2014; revised Nov. 14, 2014; accepted Nov. 14, 2014.

Author contributions:D.A. and R.R. designed research;D.A., E.T., andÉ.M. performed research;J.-P.J. contributed unpublished reagents/analytic tools; D.A., E.T., É.M., and R.R. analyzed data; D.A. and R.R. wrote the paper.

This work was supported by Canadian Institutes for Health Research Grants MOP-14137, MOP-111070, a Bernice Ramsay Discovery grant from ALS Society of Canada , Canadian Foundation of Innovation to R.R., and Fonds Recherche Quebec-Santé Leader Opportunity Fund to the Groupe de recherche sur le Système Nerveux Central infrastructure grant. D.A. held a studentship from National Science Engineering Research Council of Canada. E.T. and É.M. each held a Fonds Recherche Quebec-Santé studentship. We thank Dr. Jannic Boehm for comments over the course of this work; Dr. Christine Vande Velde for her constant support, stimulating discussions, and for reading and commenting on the manuscript; and Joanne Vallée and Julie Pépin for technical support.

The authors declare no competing financial interests.

Correspondence should be addressed to Dr. Richard Robitaille, Département de neurosciences, Université de Montréal, Montréal, Québec H3C 3J7, Canada. E-mail: richard.robitaille@umontreal.ca.

DOI:10.1523/JNEUROSCI.1379-14.2015

Copyright $\odot 2015$ the authors $\quad 0270-6474 / 15 / 350688-19 \$ 15.00 / 0$
ALS is a non-cell-autonomous disease, involving glial cells (astrocytes, microglia, and oligodendrocytes) in pathogenesis and progression (Clement et al., 2003; Boillée et al., 2006; Yamanaka et al., 2008; Wang et al., 2011; Kang et al., 2013). Also, it was shown that activation of axonal Schwann cells (myelinating and nonmyelinating) precedes the decline of motor function and the onset of hindlimb paralysis (Keller et al., 2009). However, while the impact of the mutation in axonal Schwann cells was tested (Lobsiger et al., 2009; Turner et al., 2010; Wang et al., 2012), the contribution of perisynaptic Schwann cells (PSCs), glial cells at the NMJ, remains unknown.

Interestingly, PSCs may have an important contribution in NMJ dysfunction in ALS because they are essential for the maintenance of synaptic structure and function and govern the induction and guidance of nerve terminal sprouting during reinnervation (Reynolds and Woolf, 1992; Son et al., 1996; O'Malley et al., 1999; Reddy et al., 2003; Feng and Ko, 2008). They decode synaptic transmission and regulate it in a $\mathrm{Ca}^{2+}$-dependent manner (Reist and Smith, 1992; Robitaille, 1998; Rochon et al., 2001; Colomar and Robitaille, 2004; Rousse et al., 2010; Todd et al., 2010; Darabid et al., 2013). Importantly, this decoding ability determines the fate of the NMJ because it controls PSC response to injury and regulates gene expression in PSCs via muscarinic receptors (mAChRs) (Reynolds and Woolf, 1992; Georgiou et al., 1994, 1999; Son et al., 1996). These data indicate that mAChR activation maintains PSCs in a state of maintenance, preventing 
gene expression required for NMJ repair. Hence, an altered PSC decoding ability with abnormal $\mathrm{mAChRs}$ activation would deter on PSC functions of maintenance and repair.

Because of their role as synaptic modulators and their involvement in NMJ maintenance and repair, we postulate that the decoding ability of PSCs is altered at a very early stage of disease and persist in time. To evaluate this, we used the SOD $1^{G 37 R}$ mouse model (line 29), which features a late-onset and slowly progressing phenotype (Wong et al., 1995). We report that the ability of PSCs to decode synaptic transmission is altered in SOD1 $1^{\text {G37R }}$ mice, elicited by higher muscarinic activation. Because enhanced muscarinic activation would not favor NMJ repair, this suggests that PSCs could play an important role to the onset and/or progression of the disease.

\section{Materials and Methods}

Animals

Soleus (SOL) muscles and their innervation were dissected from three animal groups: (1) transgenic mice expressing the human SOD1 gene carrying the G37R mutation (Gly $\rightarrow$ Arg $)($ line 29$)\left(S O D 1^{G 37 R}\right)$ where a moderate (4-fold to 5-fold) increase in mutated SOD1 level in brain and spinal cord was reported (Wong et al., 1995); (2) their age-matched wild-type (WT) littermates; and (3) hSOD1 transgenic mice (SOD1 ${ }^{W T}$ ), which overexpress the WT human SOD1 gene, were used as age-matched controls. The SOD1 ${ }^{G 37 R}$ were purchased from The Jackson Laboratory and maintained in a C57BL/6 genetic background. The transgenic mice were genotyped by PCR amplification for the human SOD1 gene performed on tail biopsy samples taken at the time of the weaning $(\sim 21 \mathrm{~d}$ of age). The SOD1 $1^{G 37 R}$ transgenic mice develop symptoms and pathology resembling human ALS, with paralysis in one or more limbs attributable to the eventual loss of MN from the spinal cord. SOD $1^{W T}$ have not been reported to develop ALS-like disease. SOD ${ }^{W T}$ express three times the normal level of SOD1 in the blood, brain, and fibroblasts (Audet et al., 2010).

To avoid ambiguity associated with gender-related differences, only male mice were used in the present study. Presymptomatic animals were used at postnatal day 107-130 (P120), and preonset animals were used at P357-P404 (P380). A smaller cohort of animals was used at P60. An autopsy was performed on every preonset animal. They were discarded if any sign of abnormal anatomical features of abdominal organs were observed. As proposed earlier, we refer to the onset of the disease by the peak of the body weight curve (Boillée et al., 2006). This age also coincides with initial axonal retraction from the neuromuscular synapses in the SOL (data not shown). Therefore, the disease onset was carefully monitored and assessed every week with animal weight and behavioral performances, including the presence of tremors and lack of hindlimb extension reflex (median age of onset $=426 \mathrm{~d}$ ). No animal that passed the onset point was used in this study. The fragility and the state of the nerve-muscle preparations after the onset of the disease prevented us from performing electrophysiological recordings and calcium imaging experiments with a sufficient success rate.

All experiments were performed in accordance with the guidelines for maintenance and care of animals of the Canadian Council of Animal Care and Université de Montréal.

\section{Nerve-muscle preparations}

SOL nerve-muscle preparations were pinned in a Sylgard-coated experimental chamber filled with normal Rees' Ringer's saline solution containing the following (in mM): $110 \mathrm{NaCl}, 5 \mathrm{KCl}, 1 \mathrm{MgCl}_{2}, 25 \mathrm{NaHCO}_{3}, 2$ $\mathrm{CaCl}_{2}, 11$ glucose, 0.3 glutamate, 0.4 glutamine, $5 \mathrm{BES}\left(\mathrm{C}_{6} \mathrm{H}_{15} \mathrm{NO}_{5} \mathrm{~S}\right)$, $4.34 \times 10^{-7}$ cocarboxylase, and 0.036 choline chloride. Experiments were performed at $28 \pm 2^{\circ} \mathrm{C}$ under continuous perfusion of oxygenated $\left(95 \% \mathrm{O}_{2}, 5 \% \mathrm{CO}_{2}\right)$ saline solution. The $\mathrm{pH}$ of oxygenated solution was at 7.3.

\section{Electrophysiological recordings of synaptic transmission}

Stimulation of the tibial nerve was performed using a suction electrode filled with extracellular saline. Endplate potentials (EPPs) were recorded using glass microelectrodes (1.0 mm OD; WPI) pulled to $40-70 \mathrm{M} \Omega$ (filled with $3 \mathrm{~mm} \mathrm{KCl}$ ) with a Brown-Flaming micropipette puller (Sutter Instruments). Synaptic responses were amplified by an AM Systems 1600 amplifier and further amplified $(100 \times)$ and filtered $(2 \mathrm{kHz})$ by a Warner Instruments DC amplifier. The recordings were digitized using a national Instruments BNC 2110 board and subsequently acquired with WinWCP software (John Dempster, Strathclyde University, Strathclyde, UK).

Synaptic strength of recorded NMJs was determined by measuring the paired-pulse facilitation (PPF) and the quantal content $(\mathrm{m})$. These were obtained using a low $\mathrm{Ca}^{2+}(1 \mathrm{~mm})$ and high $\mathrm{Mg}^{2+}$ (6.4 mM) Ringer's solution. PPF was obtained using two stimuli of $0.1 \mathrm{~ms}$ duration at $10 \mathrm{~ms}$ interval, elicited at $0.2 \mathrm{~Hz}$. PPF was calculated as the mean amplitude of the second EPPs divided by the mean amplitude of the first EPPs, including failures. Quantal content $(\mathrm{m})$ was determined using the amplitude of the miniature endplate potentials (MEPPs), as described previously (Del Castillo and Katz, 1954): $\mathrm{m}=$ (mean amplitude of EPPs/mean amplitude of the MEPPS). MEPP amplitude and frequency were determined using 5-10 min of recordings without motor nerve stimulation. A minimum of 100 MEPPs were used to calculate $m$ for each NMJ. Recordings with an initial membrane potential depolarized $>-65 \mathrm{mV}$ or with $>5 \mathrm{mV}$ variation from holding potential were not included for analysis. Muscle fibers were impaled $\sim 50-100 \mu \mathrm{m}$ from the NMJ to be studied, avoiding mechanical distortion of the NMJ, yet providing a morphological landmark for finding the NMJ for post hoc morphological analysis.

\section{Calcium imaging of PSCs}

Nerve-muscle preparations were incubated for $90 \mathrm{~min}(2 \times 45 \mathrm{~min})$ in a preoxygenated Ringer's saline solution containing $10 \mu \mathrm{M}$ fluo- $4 \mathrm{AM}$ (Invitrogen) and $0.02 \%$ pluronic acid (Invitrogen) at $26 \pm 1^{\circ} \mathrm{C}$. This method is known to preferentially load PSCs at NMJs (Georgiou et al., 1999; Rousse et al., 2010; Todd et al., 2010). PSCs were easily identified on surface NMJs with transmitted light microscopy. Excitation of the $\mathrm{Ca}^{2+}$ indicator (fluo-4) was achieved using the $488 \mathrm{~nm}$ line of the argon ion laser of an FV1000 Olympus confocal microscope and a $20 \times$ or a $60 \times$ water-immersion objective (respectively, $0.95 \mathrm{NA}$, XLUMPlanFl; and $0.90 \mathrm{NA}$, Olympus). Emitted fluorescence was detected using a bandpass filter (500-545 nm). Basel level of fluorescence was always set within the same range of arbitrary units, using the same software and hardware settings. Changes in fluorescence were measured by subtracting the background fluorescence from the neighboring muscle fiber, and changes in fluorescence were measured over PSC soma and expressed as follows: $\% \Delta \mathrm{F} / \mathrm{F}=(\mathrm{F}-\mathrm{F}$ rest $) / \mathrm{F}$ rest $\times 100$. Experiments were discarded when focus drift occurred.

Calcium responses evoked in PSCs by endogenous release of neurotransmitter were obtained by stimulating the tibial nerve at $50 \mathrm{~Hz}$ during $5 \mathrm{~s}$ using a suction electrode. To prevent muscle contractions, postsynaptic cholinergic receptors were blocked with D-tubocurarine chloride $(2.2-2.6 \mu \mathrm{g} / \mathrm{ml}$, Sigma), which does not affect PSC excitability (Reist and Smith, 1992; Todd et al., 2010). Preparations were allowed to stabilize with constant bath perfusion for at least 20 min before attempting motor nerve stimulation and $\mathrm{Ca}^{2+}$ imaging. In certain experiments, PSC $\mathrm{Ca}^{2+}$ responses were elicited by local application of agonists using a brief, small pulse of positive pressure (20-40 PSI, 150-200 ms) generated by a Picospritzer II (Parker Instruments) applied on a glass pipette ( 5 $\mathrm{M} \Omega, \sim 2$-mm-tip diameter) positioned in proximity of the cells. Adenosine $5^{\prime}$-triphosphate (ATP), muscarine, or acetylcholine (10 $\mu \mathrm{M}$, Sigma) was dissolved in the same Ringer's solution used for the experiment. One $\mathrm{NMJ}$ per muscle was imaged when motor nerve stimulation was applied to the preparation, but PSCs at several NMJs were imaged per muscle with agonist applications. A recovery of at least $20 \mathrm{~min}$ was allowed between each application when several applications were performed on the same cells.

\section{Antagonist applications}

In some experiments, antagonists were bath applied for at least $45 \mathrm{~min}$ before the start of experiments. $\mathrm{P} 2{ }_{\mathrm{Y}}$ antagonists (Reactive Blue 2 or RB2, $20 \mu \mathrm{M}$, Alexis), large-spectrum P2 antagonists (pyridoxalphosphate-6azophenyl-2' $2^{\prime}{ }^{\prime}$-disulfonic acid, 20, 60, and $100 \mu \mathrm{M}$, and suramin, 100 $\mu \mathrm{M}$, Sigma) and mAChRs antagonist (atropine, 5-20 $\mu \mathrm{M}$, Sigma) were diluted in the same extracellular saline solution. 


\section{TEA application}

Neurotransmitter released by either WT or $S O D 1^{G 37 R}$ nerve terminals was increased using a $\mathrm{K}^{+}$channel blocker, tetraethyl ammonium (TEA, $0.2 \mathrm{~mm}$, Sigma). TEA was bath applied for $30 \mathrm{~min}$, and synaptic activity was monitored (frequency of stimulation $=0.2 \mathrm{~Hz}$ ). Then, nerve-muscle preparations (now potentiated by TEA) were stimulated at high frequency $\left(50 \mathrm{~Hz}\right.$ for $5 \mathrm{~s}$ ), and the corresponding PSC $\mathrm{Ca}^{2+}$ responses were recorded. In some control experiments, agonists (ATP, $10 \mu \mathrm{M}$ ) were locally applied in the presence of TEA by micro-pressure as indicated above.

\section{Immunohistochemistry and confocal imaging}

Labeling of synaptic compartments. Immunohistochemical labeling of the three synaptic components at the NMJ was done according to the method previously described (Todd et al., 2010; Darabid et al., 2013). SOL muscles were dissected in oxygenated Rees' Ringer's solution and pinned in a Sylguard-coated $10 \mathrm{~mm}$ Petri dish. Muscles were then fixed for $10 \mathrm{~min}$ in $4 \%$ formaldehyde diluted in PBS buffer (in mM as follows: $137 \mathrm{NaCl}, 2.7 \mathrm{KCl}, 10 \mathrm{Na}_{2} \mathrm{HPO}_{4}, 2 \mathrm{KH}_{2} \mathrm{PO}_{4}$ ) at room temperature and permeabilized in $100 \%$ cold-methanol at $-20^{\circ} \mathrm{C}$ for $6 \mathrm{~min}$. Nonspecific labeling was blocked by incubating muscles with $10 \%$ normal donkey serum in PBS containing $0.01 \%$ Triton X-100 for $20 \mathrm{~min}$ at room temperature. First, Schwann cells were labeled with a rabbit anti-S100 $\beta$ antibody (1:250, Dako) for $2 \mathrm{~h}$, and then axons (chicken antineurofilament M [NF-M], 1:2000, Rockland Immunochemicals) and nerve terminals (mouse IgG1 anti-synaptic vesicular protein 2, 1:2000; Developmental Studies Hybridoma Bank) were labeled for 90-120 min. After washing, muscles were incubated with secondary antibodies, goat anti-mouse IgG1 Alexa-488, donkey anti-chicken Alexa-448, and donkey anti-rabbit Alexa-647 (all 1:500, Jackson ImmunoResearch Laboratories) for $1 \mathrm{~h}$. Postsynaptic nicotinic acetylcholine receptors (nAChRs) were labeled with Alexa-594-conjugated- $\alpha$-bungarotoxin (1.33-2.0 $\mu \mathrm{g}$ / $\mathrm{ml}$, Invitrogen) for 30-45 min. All antibody incubations were performed in PBS containing $0.01 \%$ Triton X-100 and $2 \%$ normal donkey serum at room temperature. After each step (except blocking), muscles were rinsed three times in PBS containing $0.01 \%$ Triton X-100 for 5 min. Muscles were then mounted in Prolong Gold antifade reagent (Invitrogen). Observations were done on an Olympus FV1000 (WT, SOD $1^{W T}$, and $S O D 1^{G 37 R}$ groups) or a Zeiss LSM 510 (C57BL/6 controls) confocal microscope. No image manipulations were performed after acquisition.

Labeling of muscle fiber type. Muscle fiber types were determined at the end of all physiological experiments. Muscles were fixed in $4 \%$ formaldehyde at room temperature for $10 \mathrm{~min}$ and rinsed with PBS $(3 \times 5 \mathrm{~min})$. Muscles were then permeabilized in 100\% cold methanol for 6 min at $-20^{\circ} \mathrm{C}$ and incubated in a solution of $10 \%$ normal donkey serum and $0.01 \%$ Triton X-100 for 20 min to minimize nonspecific labeling. Muscles were washed in PBS containing 0.01\% Triton X-100 (3 times, 5 min each) after each of the following steps. Muscles were incubated with a mouse anti-Type I myosin heavy chain IgGIIb and anti-Type IIa myosin heavy chain IgG1 (1:100-200, SC-71-c and 1:75-100, BA-D5-c, Developmental Studies Hybridoma Bank, respectively) for $120 \mathrm{~min}$ at room temperature. After rinsing in PBS $(3 \times 5 \mathrm{~min})$, preparations were incubated with CY5 or Alexa 647 anti-mouse IgGIIb (1:500) secondary antibodies for $60 \mathrm{~min}$ and then incubated with Alexa-488 anti-mouse IgG1 (1:1000) for $60 \mathrm{~min}$ at room temperature. Finally, muscles were incubated with $\alpha$-bungarotoxin (Alexa-594, 1.33-2.0 $\mu \mathrm{g} / \mathrm{ml}$ ) for $45 \mathrm{~min}$. Preparations were then mounted in Prolong Gold antifade reagent and all labels observed simultaneously using a Zeiss LSM 510 confocal microscope or the spectral detection feature of an Olympus FV1000. No further manipulations of the images were performed after acquisition.

\section{Histological analysis}

Seven criteria similar to those described in previous studies (Wright et al., 2009; Valdez et al., 2012) were used to analyze NMJ morphology and are detailed in Table 1 . We did not evaluate receptor fragmentation as this was observed on NMJs from P120 C57BL/6 controls animals (data not shown) and reported in detail previously (Wright et al., 2009; Valdez et al., 2012). Axonal diameter was not evaluated as changes in the labeling could be due to changes in NF-M expression in the disease or switch to
Table 1. Definition and criteria used in the morphological analysis of NMJs

\begin{tabular}{|c|c|c|}
\hline & Criteria & Definition \\
\hline \multirow[t]{3}{*}{ Presynaptic } & (1) Denervation & $\begin{array}{l}\text { Partial: when part of the endplate is not recovered } \\
\text { by the presynaptic nerve terminal. } \\
\text { Complete: when the presynaptic element is absent } \\
\text { from the endplate. }\end{array}$ \\
\hline & $\begin{array}{l}\text { (2) Terminal } \\
\text { sprouting }\end{array}$ & $\begin{array}{l}\text { When the presynaptic element, originating from the } \\
\text { endplate, extends at least } 20 \mu \mathrm{m} \text { away in any } \\
\text { direction or contacts another NMJ. Only sprouts } \\
\text { on NMJs fully innervated by a myelinated axon } \\
\text { were counted as originating from that NMJ. }\end{array}$ \\
\hline & (3) Polyinnervation & $\begin{array}{l}\text { When at least two distinct axons or sprouts were } \\
\text { seen entering a single postsynaptic site. Sprouts } \\
\text { from unknown origin on partially denervated } \\
\text { NMJs or NMJs without a visible large myelinated } \\
\text { axon were automatically counted as a source of } \\
\text { innervation rather than a sprout originating from } \\
\text { that endplate. }\end{array}$ \\
\hline \multirow[t]{2}{*}{ Postsynaptic } & (4) Ectopic AChR & $\begin{array}{l}\text { When two } \mathrm{nAChR} \text { clusters of at least } 3 \mu \mathrm{m} \text { of diam- } \\
\text { eter belonging to the same endplate were at } \\
\text { least separated by } 5 \mu \mathrm{m} \text {. nAChRs are considered } \\
\text { as belonging to the same endplate if they are on } \\
\text { the same muscle fiber as evaluated by back- } \\
\text { ground fluorescence or transmitted light images. }\end{array}$ \\
\hline & $\begin{array}{l}\text { (5) Faint clustered } \\
\text { nAChR }\end{array}$ & $\begin{array}{l}\text { When the postsynaptic site was noticeably faint, } \\
\text { clustered, and had a lack of organization reminis- } \\
\text { cent of an immature NMJ (Darabid et al., 2013). }\end{array}$ \\
\hline \multirow[t]{3}{*}{ Glia } & $\begin{array}{l}\text { (6) Incomplete glial } \\
\text { coverage }\end{array}$ & $\begin{array}{l}\text { When glial cells were not fully covering the presyn- } \\
\text { aptic element. Only en face NMJs were analyzed } \\
\text { because of the limited penetration of the } S 100 \beta \\
\text { antibody in the tissue. }\end{array}$ \\
\hline & (7) Glial sprouting & $\begin{array}{l}\text { Sprouting: when PSCs extended a process associated } \\
\text { with a presynaptic sprout. }\end{array}$ \\
\hline & & $\begin{array}{l}\text { Bridge: when at least one PSC extended a process at } \\
\text { least } 20 \mu \mathrm{m} \text { away or contacting another NMJ } \\
\text { without being associated with a presynaptic } \\
\text { element. }\end{array}$ \\
\hline
\end{tabular}

another isoform (neurofilament heavy). Also, the NF-M antibody did not penetrate the tissue very well such that labeling axons located under the first two layers of muscle fibers was unreliable.

The following procedure was used to ensure that the muscle fiber typing was performed on the same NMJs on which physiological measurements were performed. First, we captured an image at low magnification $(20 \times)$ to determine its position within the field of view in the microscope relative to the surrounding NMJs and the position of the main nerve entry by counting the number of fibers between them. Sometimes, the position of the nerve entry into the junction could be used as an additional criterion. Second, after electrophysiological recordings, we performed deliberate perforation of the surrounding muscle fibers with a glass pipette. The map was then used in the subsequent imaging sessions to locate the junction of interest. Third, we labeled the nAChRs with $\alpha$-bungarotoxin (Alexa-594, $10 \mu \mathrm{g} / \mathrm{ml}, 20 \mathrm{~min}$ ) for each $\mathrm{Ca}^{2+}$ imaging experiment. This toxin does not affect PSC excitability (Rochon et al., 2001). The unique "pretzel-like" pattern of the bungarotoxin-labeled nAChRs of an NMJ and of the surrounding ones served as selective markers. Also, this staining allowed us to generate a $3 \mathrm{D}$ reconstruction of the endplate to further detail its organization.

\section{Statistical analysis}

Results are presented as mean \pm SEM. $N$ represents the number of animals, and $n$ refers to the number of NMJs or PSCs. Paired $t$ tests were performed when comparing synaptic responses induced by the motor nerve stimulation during the same experiment. Unpaired $t$ tests were performed to compare two different conditions from different experiments. One-way Kruskal-Wallis ANOVA test with Dunn's Multiple- 
Comparison post-test was used to compare three groups or more. Two-way ANOVA test with Bonferroni's Multiple Comparison post-test were used when there were more than one independent variable and multiple observations for each independent variable. All tests were used at a confidence level of $95 \%(\alpha=0.05)$.

\section{Results}

The decoding ability of PSCs with $\mathrm{mAChR}$ activation represents a central element for appropriate PSC responses in the regulation of NMJ morphology and stability. Thus, we hypothesized that PSC properties could be altered at an early presymptomatic period in an ALS mouse model in which predictable NMJ destruction will occur. In this work, we investigated two fundamental PSC properties that are essential for their normal function: the regulation of morphological organization and the decoding of synaptic activity.

\section{NMJ morphology is unchanged at a presymptomatic stage}

PSCs actively participate in the maintenance and repair of neuromuscular synapses (Reynolds and Woolf, 1992; Son et al., 1996; Georgiou et al., 1999; O’Malley et al., 1999; Reddy et al., 2003; Feng and Ko, 2008). Hence, any sign of PSC morphological disorganization coupled to NMJ morphological alteration would be a clear and sensitive sign of PSCs' inability to maintain NMJ integrity.

To distinguish between the impacts of the mutated SOD1 protein and the overexpression of the human WT SOD1 protein, we analyzed the NMJ morphology at an asymptomatic stage of the disease (P120) using immunohistological labeling of PSCs, presynaptic and postsynaptic elements from WT, SOD $1^{W T}$, and $S O D 1^{G 37 R}$ animals (Fig. 1A). Seven previously documented NMJ-related alterations (Table 1) were quantified from images, such as those shown in Figure $1 A$ (described in Experimental procedures). Only $12 \%$ of NMJs of WT, $19 \%$ of NMJs of SOD $1^{W T}$, and $11 \%$ of NMJs of SOD $1^{G 37 R}$ exhibited one or two of the seven criteria (Table 2; no statistical difference between any of these criteria in the different groups). For instance, the presynaptic terminal branch morphology or postsynaptic receptor appearance was unaltered, and all NMJs of each group were innervated (Fig. 1A; Table 2). Consistent with O'Malley et al. (1999), we found that PSC somata and processes were precisely aligned with nerve terminal branches and postsynaptic ACh receptors (O'Malley et al., 1999) (Fig. 1A; Table 2). Hence, these results reveal that NMJs from $S O D 1^{G 37 R}$ were indistinguishable from WT and SOD $1^{W T}$ at P120.

We next examined whether the proportion of Type I and Type IIa fibers was different at this age. This was tested using specific antibodies against MHC isoform Types I and IIa, corresponding to the slow and fast fatigue-resistant muscle fibers, respectively, present in the SOL muscle (Fig. $1 B$ ). All unlabeled fibers were identified as fiber IIx, the remaining fiber subtype in the SOL (Valdez et al., 2012). However, as shown in Figure $1 C$ and as previously reported in a young adult C57BL/6 mouse (Valdez et al., 2012) and SOD $1^{W T}$ mice (Hegedus et al., 2007), we found no difference in the proportion of fiber types (WT: $N=5$ muscles, $n=295$ fibers; SOD $1^{W T}: N=4$ muscles, $n=220$ fibers; $S O D 1^{G 37 R}: N=5$ muscles, $n=295$ fibers; Fig. 1C, two-way ANOVA, $F=0.83, p=0.5158)$. Finally, there was no significant difference in the percentage of NMJs per muscle associated with each fiber type (WT: $N=5$ muscles, $n=176$ NMJs; SOD $1^{W T}$ : $N=4$ muscles, $n=147$ NMJs; SOD $1^{G 37 R}: N=5$ muscles, $n=154$ NMJs; Fig. $1 D$, two-way ANOVA, $F=1.61, p=0.1951$ ).

Thus, neither the overall number of NMJs according to the fiber type nor the morphology was altered at P120 of WT,
SOD $1^{W T}$, and SOD $1^{G 37 R}$ mice. This suggests that PSC properties that ensure the stability of the neuromuscular synapse were normal at this early age and stage of the disease.

\section{Excitability of PSCs is altered early at P120}

PSCs regulate morphological stability and integrity and actively participate in the reinnervation of the NMJ, events that are under the influence of synaptic communication. Indeed, in healthy conditions, interruption of synaptic communication between PSCs and presynaptic nerve terminals leads to changes in PSCs phenotype that facilitate NMJ plasticity and reinnervation (Reynolds and Woolf, 1992; Son et al., 1996; O’Malley et al., 1999). Importantly, the PSC switch from maintenance mode to repair mode is regulated by their ability to detect synaptic transmission (Georgiou et al., 1994, 1999), suggesting that their role as synaptic modulators is tightly linked to synaptic maintenance and repair.

Thus, we examined the ability of PSCs to respond to synaptic activity elicited by motor nerve stimulation. Stimulation was performed at $50 \mathrm{~Hz}$ for $5 \mathrm{~s}$, a frequency reported for firing of motor neurons innervating adult SOL muscle (Chipman et al., 2010) and for PSC responsiveness (Todd et al., 2007; Rousse et al., 2010). PSC activity was assessed by monitoring changes in intracellular $\mathrm{Ca}^{2+}$ levels, which is a well-known and reliable reporter of their level of excitation and responsiveness (Robitaille, 1998; Rochon et al., 2001; Rousse et al., 2010; Darabid et al., 2013).

As shown in Figure $2 A$, synaptic activity evoked by stimulation of the motor nerve induced $\mathrm{Ca}^{2+}$ responses in PSCs. As indicated by the number of cells activated, the propensity of PSCs to respond to synaptic activity was similar for NMJs from both control groups (WT: 58\%, 22 PSCs activated out of 38; SOD1 ${ }^{W T}$ : $47 \%, 8$ PSCs activated out of 17$)$ and the SOD $1^{\text {G37R }}$ mice $(58 \%, 22$ activated PSCs out of 38). However, and somewhat surprisingly, the amplitude of PSC $\mathrm{Ca}^{2+}$ responses was larger in $\mathrm{SOD} 1^{\mathrm{G} 37 R}$ mice. Indeed, the average amplitude of $\mathrm{PSC} \mathrm{Ca}^{2+}$ responses from WT mice and SOD $1^{W T}$ was $34.3 \pm 4.3 \% \Delta \mathrm{F} / \mathrm{F}$ and $24.1 \pm 2.8 \%$ $\Delta \mathrm{F} / \mathrm{F}$, respectively, whereas it was $108.9 \pm 18.1 \% \Delta \mathrm{F} / \mathrm{F}$ from $S O D 1^{G 37 R}$ mice (Fig. $2 B ; N=10, n=22$ for WT, $N=5, n=8$ for $S O D 1^{W T}$ and $N=9, n=22$ for $S O D 1^{G 37 R}$, one-way ANOVA, $p=$ $0.0004)$. However, this difference was not observed at an earlier age (P60) (data not shown; $N=5, n=9$ for WT and $N=4, n=$ 10 for $S O D 1^{G 37 R}$, unpaired $t$ test, $\left.p=0.3065\right)$. These results indicate that the PSCs at NMJs of an ALS mouse model at P120 detected transmitter release but with an enhanced excitability.

We next tested whether PSC excitability reflected MN properties because MNs differ not only in their physiological properties but also in their anatomical plasticity and susceptibility to loss of neuromuscular connectivity. This was tested by performing immunohistological staining of $\mathrm{MHC}$ isoforms after each $\mathrm{Ca}^{2+}$ imaging experiment (Fig. 2C). Because PSC $\mathrm{Ca}^{2+}$ responses from WT and $S O D 1^{W T}$ mice were indistinguishable, we compared only the WT and the SOD1 ${ }^{G 37 R}$ groups for these experiments. As shown in Figure $2 \mathrm{D}, \mathrm{Ca}^{2+}$ response amplitude from $S O D 1^{G 37 R}$ was 3.0- to 3.5-fold larger than WT for each fiber type (MHC-I: $N=4, n=8$ for WT and $N=4, n=9$ for $S O D 1^{G 37 R}$, unpaired $t$ test, $p=0.0279$ ) (MHC-IIa: $N=7, n=12$ and for WT and $N=$ $4, n=8$ for $S O D 1^{G 37 R}$, unpaired $t$ test, $\left.p=0.0021\right)$. Together, these results suggest that alterations in PSC $\mathrm{Ca}^{2+}$ responses do not correlate with the predicted and specific vulnerability of MNs at this presymptomatic stage of the disease. These alterations are expressed at least 4 months before the earliest signs of sensorimo- 


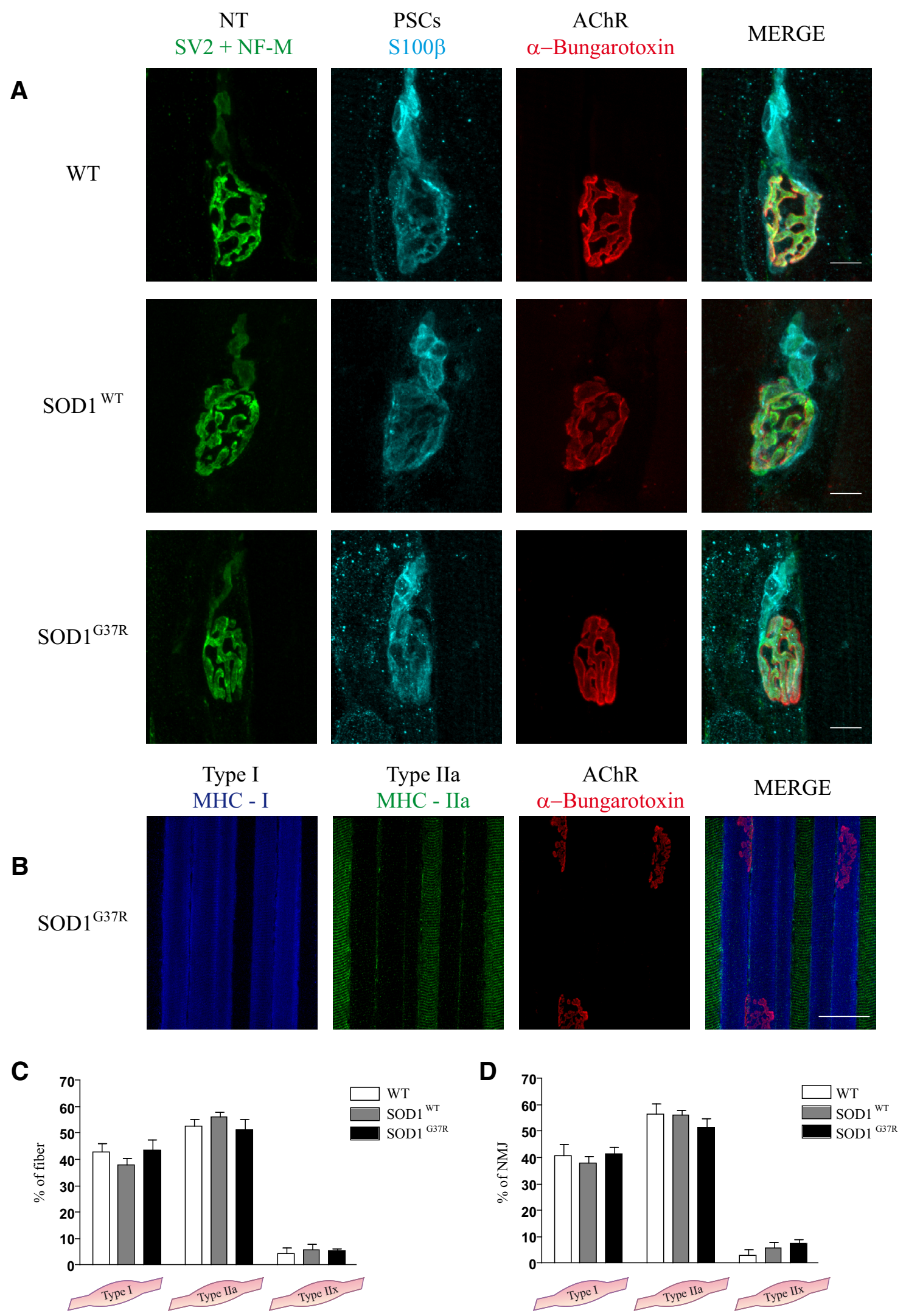

Figure 1. Morphology is unaltered at presymptomatic stage of the disease. $A$, Confocal images of NMJs from controls (WT and SOD1 ${ }^{W T}$ ) and an ALS mouse model (SOD1637R). P120 soleus NMJs were labeled for the nerve terminals (NT) (synaptic vesicular protein 2 and NF-M, green), PSC (S100 $\beta$, cyan), and postsynaptic nAChRs ( $\alpha$-bungarotoxin, red). Note the similar staining patterns between each animal group. $\boldsymbol{B}$, Confocal images of soleus muscle from an SOD ${ }^{G 37 R}$ mouse. Muscle fibers were stained using anti-myosin heavy chain (MHC) monoclonal antobodies: Type I fibers (MHC-l; blue), Type lla fibers (MHC-Ila; green), and $\alpha$-bungarotoxin (red) to identify the localization of the endplates. Note the alternation of slow- and fast-twitch fibers in the soleus muscle. C, Histogram of the percentage of surface fibers in the soleus of each animal group. $\boldsymbol{D}$, Histogram of the percentage of surface NMJs per fiber type in the soleus of each animal groups. Histograms in $\boldsymbol{C}$ and $\boldsymbol{D}$ represent mean \pm SEM. Scale bars: $\boldsymbol{A}, 10 \mu \mathrm{m} ; \boldsymbol{B}, 50 \mu \mathrm{m}$. 
Table 2. Percentage of NMJs that meet criteria used in the morphological analysis for each animal group

\begin{tabular}{|c|c|c|c|c|c|}
\hline & Criteria & WT & SOD1 ${ }^{\text {WT }}$ & SOD1 ${ }^{\text {G37R }}$ & $p$ \\
\hline \multirow[t]{3}{*}{ Presynaptic } & (1) Denervation & 0 & $1.3 \pm 1.3$ & 0 & 0.4053 \\
\hline & (2) Terminal sprouting & $1.0 \pm 1.0$ & $2.3 \pm 2.3$ & 0 & 0.5589 \\
\hline & (3) Polyinnervation & 0 & $3.0 \pm 1.8$ & 0 & 0.1007 \\
\hline \multirow[t]{2}{*}{ Postsynaptic } & (4) Ectopic AChR & 0 & $11.4 \pm 3.7$ & $2.5 \pm 1.4$ & 0.3939 \\
\hline & (5) Faint clustered nAChR & $9.2 \pm 3.4$ & $11.4 \pm 3.7$ & $6.4 \pm 2.6$ & 0.5648 \\
\hline \multirow[t]{2}{*}{ Glia } & (6) Incomplete glial coverage & 0 & 0 & 0 & NA \\
\hline & (7) Glial sprouting & $2.8 \pm 1.7$ & $2.8 \pm 2.8$ & $3.2 \pm 1.9$ & 0.9871 \\
\hline
\end{tabular}

NA, Not applicable.

A

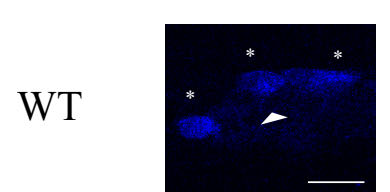

1. Baseline

2. Stimulation

3. Recovery
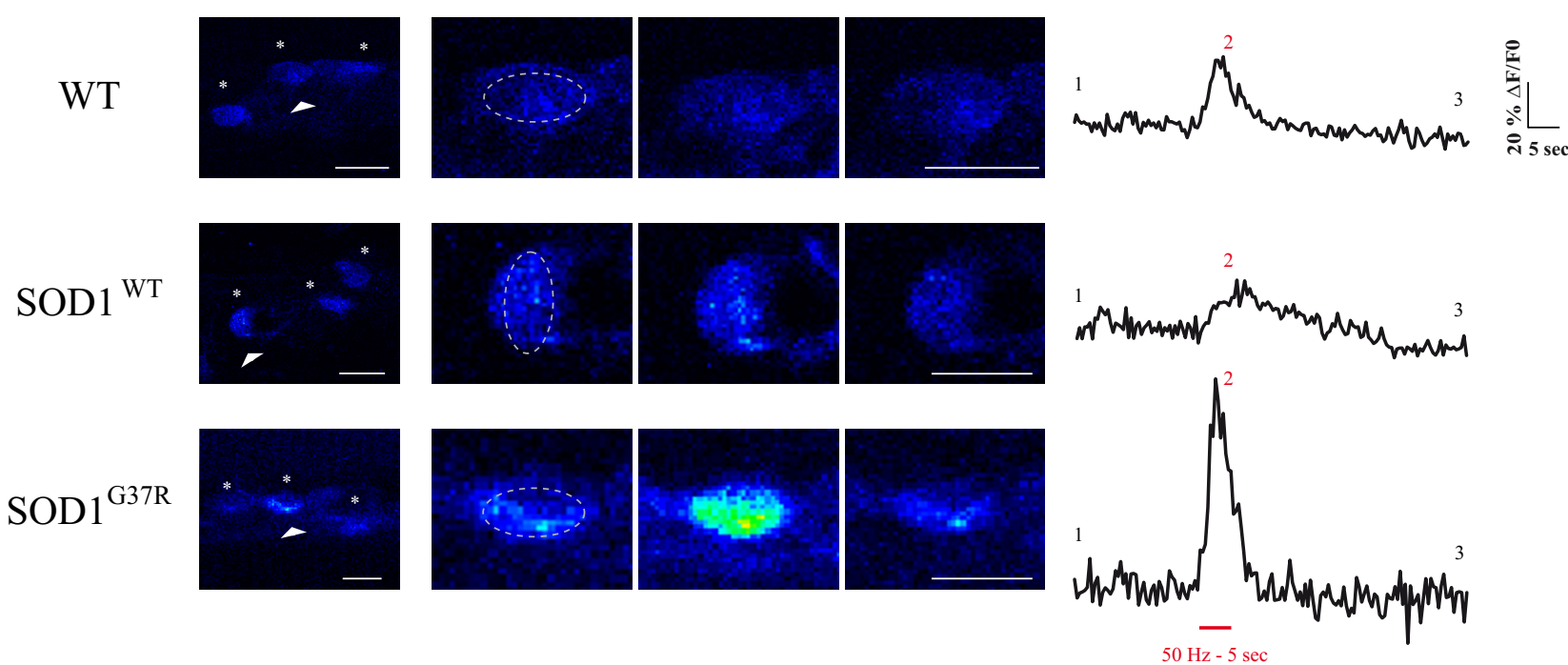

B

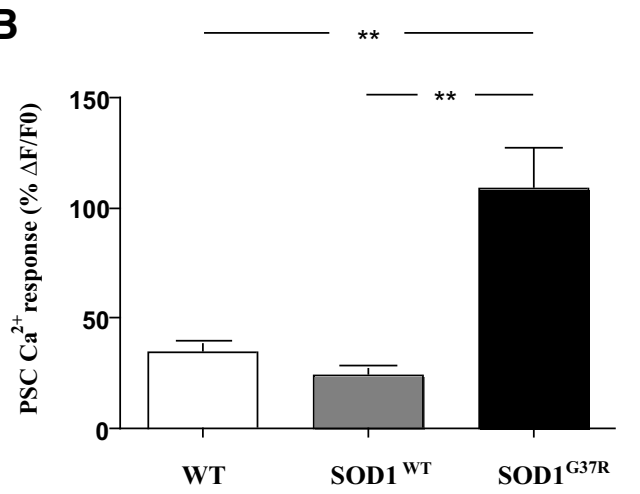

C Fluo $4 \mathrm{AM}+$ $\alpha$-Bungarotoxin

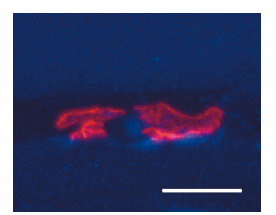

MHC - I + MHC - IIa + $\alpha$-Bungarotoxin

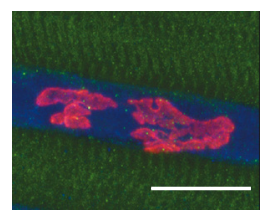

D

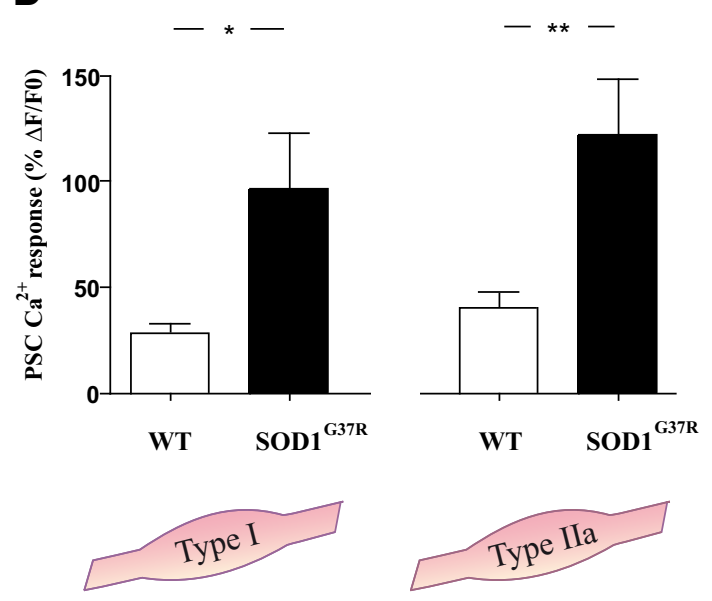

Figure 2. Altered PSC excitability at presymptomatic stage of the disease. A, False color images of PSCs $\left(^{*}\right)$ loaded with fluorescent $\mathrm{Ca}^{2+}$ indicator Fluo-4 AM, before (baseline), during (stimulation), and after (recovery) motor nerve stimulation at NMJs of WT, SOD1 ${ }^{W T}$, and SOD $1^{637 R}$. Representative changes in fluorescence are illustrated on the right for the PSCs indicated by the arrowhead. $\boldsymbol{B}$, Histogram depicting the mean \pm SEM of the amplitude of the $\mathrm{Ca}^{2+}$ responses elicited in PSCs by transmitter release evoked by motor nerve stimulation ( $\left.50 \mathrm{~Hz}, 5 \mathrm{~s}\right)$. PSCs at NMJs from SOD $1^{637 R}$ mice had larger $\mathrm{Ca}^{2+}$ responses (one-way ANOVA, $\left.p=0.0004\right) C$, Examples of an NMJ imaged during $\mathrm{Ca}^{2+}$ imaging experiment (top) and the same NMJ imaged after MHC and BTX staining (bottom). This NMJ was associated with a fiber Type I (MHC-I, blue) and not a fiber Type lla (MHC-lla, green). D, Histogram illustrating the mean \pm SEM of the amplitude of the Ca ${ }^{2+}$ responses elicited in PSCs by motor nerve stimulation as a function of each fiber type. The altered PSC excitability did not correlate with motor neuron vulnerability at a presymptomatic stage of the disease. Scale bars: $A, 10 \mu \mathrm{m} ; \boldsymbol{C}, 20 \mu \mathrm{m} .{ }^{*} p<0.05,{ }^{* *} p<0.01$.

tor and cognitive dysfunctions in this $S O D 1^{G 37 R}$ transgenic mouse model of ALS (Filali et al., 2011).

Neurotransmitter release is increased in the soleus muscle of an ALS mouse model at P120

Next, we tested the hypothesis that the synaptic strength from $S O D 1^{G 37 R}$ mice might be altered. This would be consistent with the early alterations in MN excitability (Pieri et al., 2003; Kuo et al., 2004; Amendola et al., 2007; Bories et al., 2007) that seems to diminish toward the symptomatic stage of the disease (Delestrée et al., 2014) and with the properties of PSCs at immature and mature NMJs, which decode different levels of synaptic activity by producing different $\mathrm{Ca}^{2+}$ responses (Rousse et al., 2010; Todd et al., 2010; Darabid et al., 2013). To this end, we performed 
A

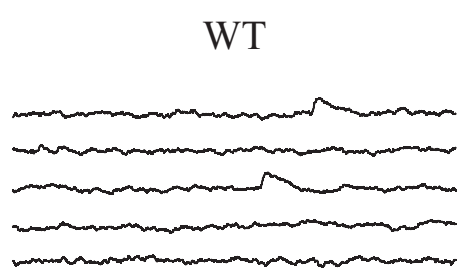

B

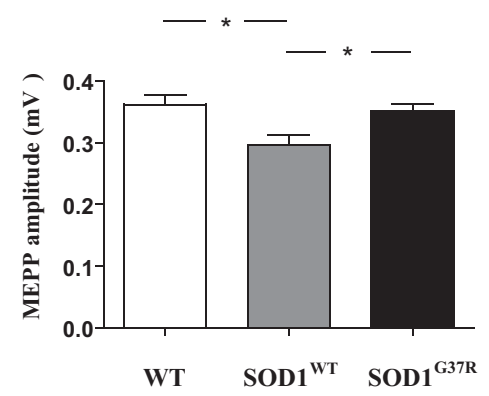

D

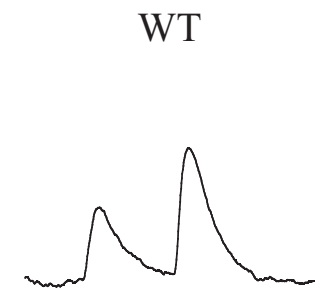

E

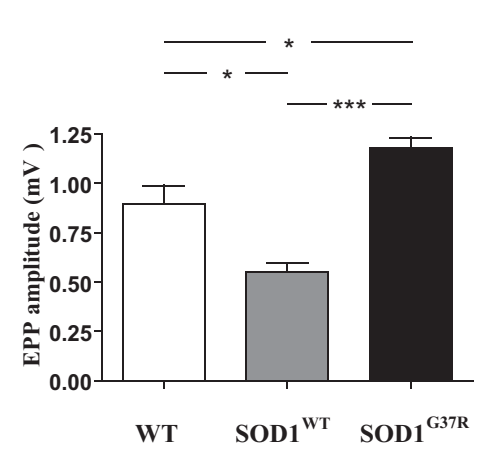

C

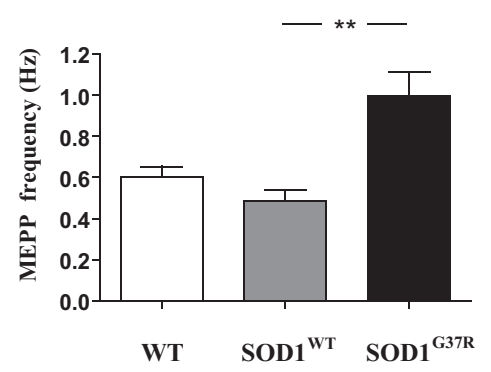

SOD1 ${ }^{\text {WT }}$

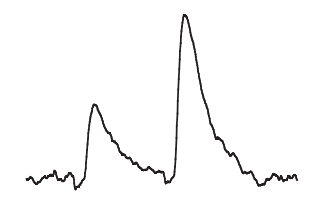

F

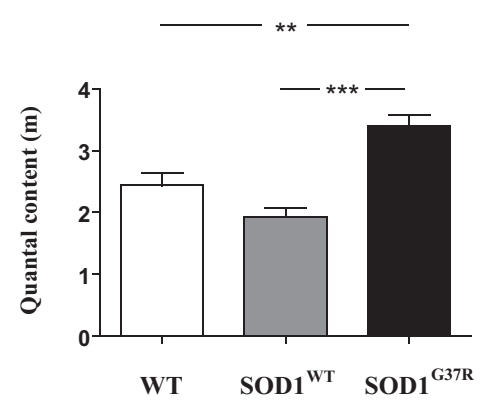

SOD1 ${ }^{\text {wT }}$
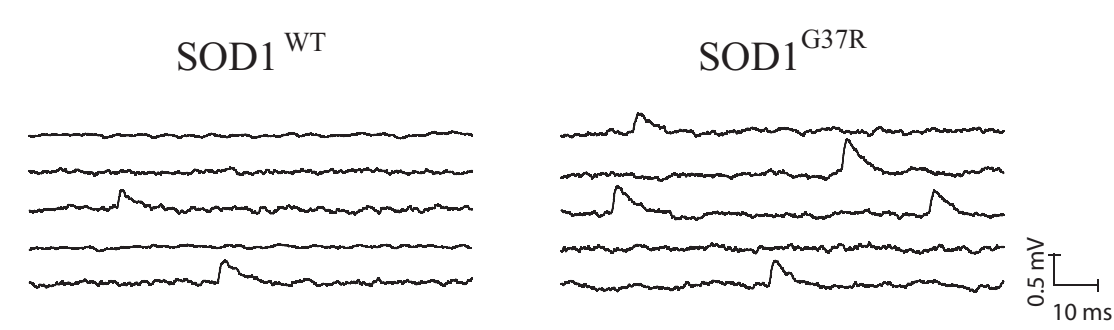

G

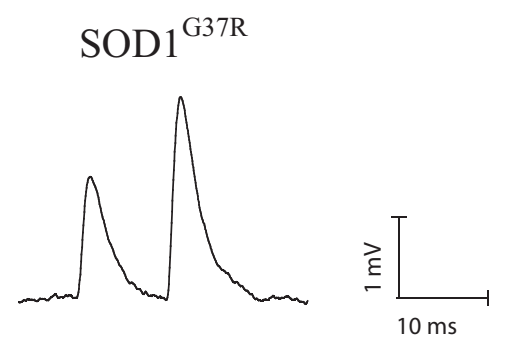

Figure 3. Enhanced synaptic transmission at NMJs from SOD $1^{G 37 R}$ mice at presymptomatic stage of the disease. $A$, Examples of spontaneous MEPP recordings from WT, SOD $1^{W T}$, and SOD ${ }^{637 R}$ NMJs. Histogram showing the mean \pm SEM of the amplitude $(\boldsymbol{B})$ and the frequency $(\boldsymbol{C})$ of the MEPP. $\boldsymbol{D}$, Examples of EPPs evoked by paired-pulse stimulation of the motor nerve (10 $\mathrm{ms}$ interval) from WT, SOD $1^{W T}$, and SOD $7^{637 R}$ NMJs. E, Histogram showing the mean \pm SEM of the amplitude of the first EPP. F, Calculated quantal content obtained from electrophysiological recordings of synaptic transmission and determined as EPP amplitude/mEPP amplitude. NMJs from SOD $1^{G 37 R}$ mice had higher quantal content. G, Calculated PPF obtained from electrophysiological recordings of synaptic transmission and determined as the mean amplitude of the second EPPs divided by the mean amplitude of the first EPPs. ${ }^{*} p<0.05,{ }^{* *} p<0.01,{ }^{* * *} p<0.001$.

intracellular recordings from WT, SOD $1^{W T}$, and $S O D 1^{G 37 R}$ NMJs. Synaptic strength was determined using the quantal content $(\mathrm{m})$ and PPF.

First, we evaluated the spontaneous activity of the NMJs. No difference in MEPP amplitude was observed between WT and SOD $1^{G 37 R}$ mice (WT, $0.36 \pm 0.01 \mathrm{mV}, N=9, n=15 ; S O D 1^{W T}$, $0.30 \pm 0.02 \mathrm{mV}, N=6, n=8 ; S O D 1^{G 37 R}, 0.35 \pm 0.01 \mathrm{mV}, N=$ $9, n=14$; one-way ANOVA, $p=0.0145$; Fig. $3 A, B)$. Surprisingly, MEPP amplitude from SOD ${ }^{W T}$ mice was slightly but significantly smaller than the WT and the $S O D 1^{G 37 R}$ mice (Fig. $3 A, B$ ). Importantly, however, MEPP frequency was significantly in- creased in the SOL muscle of the SOD $1^{\text {G37R }}$ mice (Fig. $3 A$ ) where it was $0.60 \pm 0.05 \mathrm{~Hz}$ for the WT mice, $0.48 \pm 0.05 \mathrm{~Hz}$ for the $S O D 1^{W T}$ mice, and $0.99 \pm 0.12 \mathrm{~Hz}$ for the $S O D 1^{G 37 R}$ mice (Fig. $3 C ; N=8, n=16$ for WT, $N=6, n=8$ for $S O D 1^{W T}$ and $N=8$, $n=14$ for $S O D 1^{G 37 R}$, one-way ANOVA, $\left.p=0.0008\right)$. Importantly, a difference in MEPP frequency was observed between WT and SOD $1^{G 37 R}$ mice in Type I fibers (data not shown; $N=4, n=$ $8,0.50 \pm 0.04 \mathrm{~Hz}$ for WT and $N=5, n=6,0.66 \pm 0.06 \mathrm{~Hz}$ for SOD $1^{G 37 R}$, unpaired $t$ test, $\left.p=0.0475\right)$ and Type IIa fibers $(N=$ $5, n=7,0.72 \pm 0.09 \mathrm{~Hz}$ for WT and $N=5, n=7,1.27 \pm 0.13 \mathrm{~Hz}$ for $S O D 1^{G 37 R}$, unpaired $t$ test, $\left.p=0.0045\right)$. These results are 

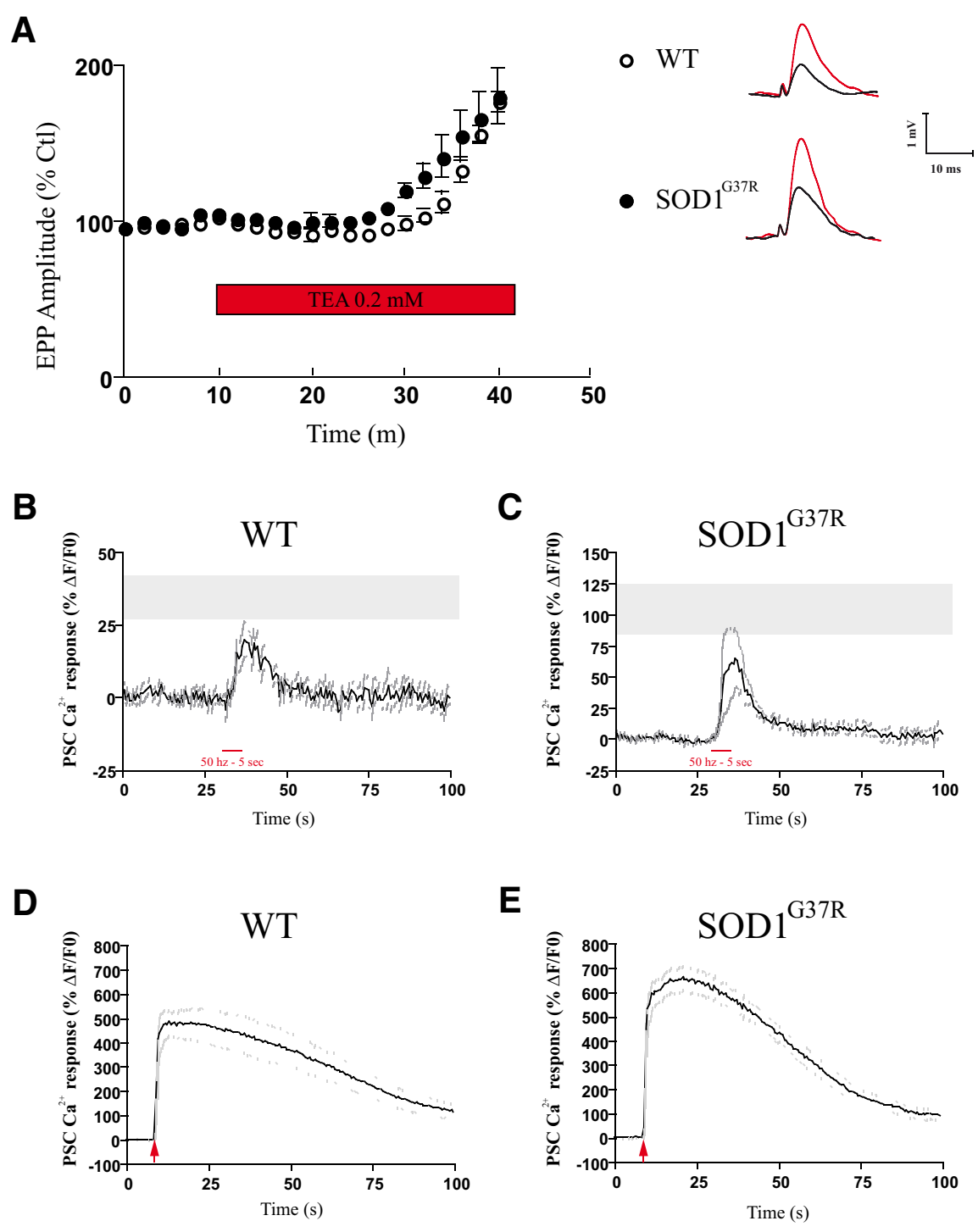

Figure 4. PSC decoding ability is unaffected by an increase in transmitter release. $A$, Changes of EPP amplitude before and during (red bar) bath application of TEA $(0.2 \mathrm{mM})$. Insets, Examples of EPPs (black) before and 30 min after TEA application (red). TEA increased synaptic transmission of both WT and SOD1 ${ }^{\mathrm{G} 37 R}$ nerve terminals. Effect of TEA $(0.2 \mathrm{mM})$ bath application on corresponding PSC $\mathrm{Ca}^{2+}$ responses induced by synaptic activity $(50 \mathrm{~Hz}, 5 \mathrm{~s})$ from WT $(\boldsymbol{B})$ and $\mathrm{SOD}^{\mathrm{G} 37 \mathrm{R}}(\boldsymbol{C})$ animals. Gray zones represent the mean $\pm \mathrm{SEM}$ of the amplitude of the $\mathrm{Ca}^{2+}$ responses elicited by motor nerve stimulation in control (without TEA). PSC $\mathrm{Ca}^{2+}$ responses elicited by potentiated WT nerve terminals remain smaller than those triggered by the $S O D{ }^{637 R}$ and were not significantly different from the ones without TEA (unpaired $t$ test, $p>0.05) . \mathrm{Ca}^{2+}$ responses elicited in PSCs by local applications of ATP in WT (D) and SOD $1{ }^{G 37 R} \mathrm{NMJs}(\boldsymbol{E})$. The ability of PSCs to produce $\operatorname{larger} \mathrm{Ca}^{2+}$ responses was not affected by TEA because local application of ATP (red arrow) elicited larger $\mathrm{Ca}^{2+}$ responses in PSC from WT and $S O D 1^{G 37 R}$ mice. In $\boldsymbol{B}-\boldsymbol{D}$, black and grey traces represent the mean and SEM, respectively.

consistent with changes of the presynaptic mechanisms of transmitter release.

Second, we evaluated the nerve-evoked activity of the NMJs. Amplitude of nerve-evoked EPPs (Fig. 3D; stimulation at $0.2 \mathrm{~Hz}$ ) in the SOD1 $1^{\text {G37R }}(1.18 \pm 0.05 \mathrm{mV}, N=9, n=14)$ was significantly larger than WT $(0.89 \pm 0.09 \mathrm{mV}, N=9, n=15)$ and SOD $1^{W T}$ $(0.55 \pm 0.05 \mathrm{mV}, N=5, n=8)$ (Fig. $3 D, E$; one-way ANOVA, $p<0.0001)$. Again, data from SOD1 $1^{W T}$ mice was significantly smaller than the WT and the SOD $1^{G 37 R}$ mice.

Third, and consistent with these observations, quantal content of NMJs from SOD $1^{G 37 R}$ mice $(3.40 \pm 0.18$, and $N=9, n=$ 14) was significantly higher compared with WT (2.44 \pm 0.20 , $N=9, n=15)$ and SOD $1^{W T}$ mice $(1.93 \pm 0.14, N=5, n=8)$ (Fig. 3F; one-way ANOVA, $p<0.0001$ ). Moreover, the quantal content in Type I fibers for the $S O D 1^{G 37 R}$ was significantly higher than the WT mice (data not shown; $N=5$, $n=9,2.41 \pm 0.28$ for WT and $N=5, n=$ $6,3.35 \pm 0.19$ for $S O D 1^{G 37 R}$, unpaired $t$ test, $p=0.0269)$ but not in Type IIa fibers $(N=5, n=5,2.71 \pm 0.27$ for WT and $N=5, n=7,3.43 \pm 0.32$ for SOD $1^{G 37 R}$, unpaired $t$ test, $p=0.1363$ ). Interestingly, these alterations in synaptic properties did not follow the typical prediction that stronger synapses should present smaller PPF (Mallart and Martin, 1968). Indeed, the SOD $1^{G 37 R}$ NMJs had a PPF value similar to the two control groups (Fig. 3G; WT, $1.33 \pm 0.03, N=9, n=15 ; S O D 1^{W T}$, $1.33 \pm 0.03, N=5, n=8 ; S O D 1^{G 37 R}$, $1.36 \pm 0.02, N=9, n=14$; one-way ANOVA, $p=0.6966$ ).

As a whole, this detailed synaptic analysis suggests that complex presynaptic alterations result in an enhancement of neurotransmitter release in $S O D 1^{G 37 R}$ mutants, primarily in Type I fibers.

\section{Decoding ability also relies on PSC intrinsic properties at $\mathrm{P} 120$}

Because PSCs are sensitive to transmitter release, one could argue that large $\mathrm{Ca}^{2+}$ response amplitude in SOD $1^{G 37 R}$ may be due to a larger level of transmitter release at these NMJs. However, it has been demonstrated, at immature and adult NMJs, that the decoding ability of PSCs also relies on their intrinsic properties (Rousse et al., 2010; Darabid et al., 2013). Hence, we examined whether the increase in transmitter release could be sufficient to explain the level of PSCs excitability or if their intrinsic properties are at play.

To discriminate between these two possibilities, we argued that, if the difference in PSCs activity between WT and SOD $1^{G 37 R}$ was solely dependent on the level of transmitter release, increasing transmitter release should result in a direct change in the amplitude of PSC $\mathrm{Ca}^{2+}$ responses. Because quantal content from WT and SOD $1^{W T}$ mice was not significantly different (Fig. 3F), we compared $S O D 1^{G 37 R}$ mice with WT littermates for these experiments. We monitored nerve-evoked $\mathrm{Ca}^{2+}$ responses in PSCs while potentiating transmitter release using a $\mathrm{K}^{+}$channel blocker (TEA, $0.2 \mathrm{~mm}$ ), which does not directly affect PSCs (Rousse et al., 2010; Darabid et al., 2013). As shown in Figure 4A, TEA significantly increased EPP amplitude approximately twofold, as expected, in WT (Ctrl, $0.79 \pm 0.01$, TEA, $1.51 \pm 0.02, N=$ 4; paired $t$ test $p<0.0001$ ) and in $S O D 1^{G 37 R}$ (Ctrl, $1.08 \pm 0.02$, TEA $1.95 \pm 0.02, N=4$; paired $t$ test $p<0.0001)$. PSC excitability appears unaltered by TEA because $\mathrm{Ca}^{2+}$ responses elicited by local application of agonists were unaffected (data not shown).

Interestingly, even though transmitter release was doubled, bath application of TEA had no effect on the average amplitude of PSC $\mathrm{Ca}^{2+}$ responses on WT synapses induced by nerve stimulation $(50 \mathrm{~Hz}$ for $5 \mathrm{~s}$ ) (Fig. $4 B ; 26.2 \pm 5.2 \% \Delta \mathrm{F} / \mathrm{F}, N=4, n=6$, 
unpaired $t$ test, $p=0.3650)$. Similar results were obtained when potentiating the $S O D 1^{G 37 R}$ synapses (Fig. $4 C ; 77.6 \pm 29.9 \% \Delta \mathrm{F} / \mathrm{F}$, $N=4, n=9$, unpaired $t$ test, $p=0.3666$ ). In addition, the percentage of responsive cells remained unchanged in WT and SOD $1^{G 37 R}$. Importantly, this cannot be explained by a saturation of the $\mathrm{Ca}^{2+}$ signal or the inability of PSCs to produce larger $\mathrm{Ca}^{2+}$ responses because larger $\mathrm{Ca}^{2+}$ responses were elicited when ATP was applied locally on the cells monitored following nerve-evoked stimulation (Fig. 4D; WT: $521.4 \pm 56.3 \% \Delta$ F/F, $N=4, n=10$; Fig. $\left.4 E ; S O D 1^{G 37 R}: 680.2 \pm 51.8 \% \Delta \mathrm{F} / \mathrm{F}, N=4, n=6\right)$. These results are consistent with previous observations (Rousse et al., 2010; Darabid et al., 2013) and indicate that an acute increase of neurotransmitter release cannot explain PSC properties in SOD1 $1^{G 37 R}$ mice. This strongly suggests that PSC decoding of synaptic activity in an ALS mouse model relies on their intrinsic properties.

\section{PSC ability to detect purinergic and muscarinic signals is unaltered at P120}

At adult mammalian NMJ, ACh and ATP released during synaptic activity activate PSC purinergic and muscarinic receptors to elicit $\mathrm{Ca}^{2+}$ responses (Rochon et al., 2001). Hence, one possible mechanism that might explain the difference in the decoding ability of PSCs of WT and SOD $1^{G 37 R}$ to nerve terminal stimulation is that PSC detection of these neurotransmitters may be altered. In this scenario, one would predict that $\mathrm{Ca}^{2+}$ responses elicited by local application of agonists for these receptors should also be altered in SOD $1^{\text {G37R }}$.

The ability of PSCs to detect ATP applied locally was examined first. Local application of ATP $(10 \mu \mathrm{M})$ induced $\mathrm{Ca}^{2+}$ responses in $100 \%$ of PSCs with a mean of $564.0 \pm 25.8 \% \Delta \mathrm{F} / \mathrm{F}$ $(N=6, n=49)$ for the WT, $463.7 \pm 27.8 \% \Delta \mathrm{F} / \mathrm{F}(N=4, n=33)$ for $S O D 1^{W T}$, and $525.4 \pm 22.3 \% \Delta \mathrm{F} / \mathrm{F}(N=6, n=55)$ for $S O D 1^{G 37 R}$ (Fig. 5A). There was no significant differences between these amplitudes (Fig. 5B; one-way ANOVA, $p=0.0917$ ). Also, we found no significant difference in $\mathrm{Ca}^{2+}$ responses associated with Type I fibers (Fig. 5C; $N=4, n=27$ for WT and $N=3, n=$ 13 for SOD $1^{G 37 R}$, unpaired $t$ test, $\left.p=0.5544\right)$ or Type IIa fibers $\left(N=3, n=12\right.$ for WT and $N=4, n=21$ for $S O D 1^{G 37 R}$, unpaired $t$ test, $p=0.6259)$.

We next investigated the ability of a muscarinic agonist to evoke $\mathrm{Ca}^{2+}$ responses (Fig. 5D-F). Muscarine $(10 \mu \mathrm{M})$ induced $\mathrm{Ca}^{2+}$ responses in $67.9 \%$ of PSCs of WT (36 of 53 PSCs), $48.9 \%$ of PSCs for SOD1 $1^{W T}$ (23 of 47 PSCs), and 50.8\% of PSCs for $S O D 1^{G 37 R}$ (31 of 61 PSCs). Local application of muscarine induced $\mathrm{Ca}^{2+}$ responses with a mean of $173.5 \pm 29.5 \% \Delta \mathrm{F} / \mathrm{F}(N=$ $9, n=36)$ for the WT, $208.1 \pm 36.8 \% \Delta \mathrm{F} / \mathrm{F}(N=4, n=23)$ for $S O D 1^{W T}$, and $200.8 \pm 28.0 \% \Delta \mathrm{F} / \mathrm{F}(N=8, n=31)$ for $S O D 1^{G 37 R}$ (Fig. 5D). These responses were not statistically different (Fig. 5E; one-way ANOVA, $p=0.6294$ ). Similar results were obtained when ACh was locally applied (data not shown). We also tested whether PSC detection reflected MN properties. Similar to our observation using ATP local applications, we found no significant difference between $\mathrm{Ca}^{2+}$ response amplitude from PSCs associated with Type I fibers for WT and $S O D 1^{G 37 R}$ mice (Fig. 5F; $N=5, n=19$ for WT and $N=5, n=11$ for $S O D 1^{G 37 R}$, unpaired $t$ test, $p=0.2081$ ) and Type IIa fibers (Fig. $5 F ; N=5, n=13$ for WT and $N=4, n=14$ for SOD $1^{G 37 R}$, unpaired $t$ test, $p=0.9285$ ).

Together, these results indicate that PSC receptors are present and functional in this ALS mouse model at P120. Moreover, the PSC detection of local application of agonist appears normal, and this cannot explain the difference in PSC $\mathrm{Ca}^{2+}$ response evoked by synaptic activity.

\section{PSC muscarinic detection of synaptic transmission is enhanced in mutant SOD1 mice at P120}

The lack of difference in $\mathrm{Ca}^{2+}$ responses of WT and $S O D 1^{G 37 R}$ mice could be explained by the fact that local applications of agonist activated PSC synaptic and extrasynaptic receptors, whereas nerve-evoked $\mathrm{Ca}^{2+}$ responses were induced by a subset of receptors during synaptic communication. This mechanism is at play to allow PSCs to distinguish two competing terminals at poly-innervated NMJs (Darabid et al., 2013). If this was the case, selective antagonism of each type of receptor should differentially alter PSC nerve-evoked $\mathrm{Ca}^{2+}$ responses of SOD $1^{\text {G37R }}$ compared with WT. Because of the rundown of $\mathrm{Ca}^{2+}$ responses (Jahromi et al., 1992; Rochon et al., 2001), each preparation was stimulated once and amplitude of $\mathrm{Ca}^{2+}$ responses elicited by nerve stimulation presented in Figure $2 B$ was used as control.

First, we examined the impact of purinergic receptor blockade using broad-spectrum P2 receptor antagonists (pyridoxalphosphate-6azophenyl-2',4'-disulfonic acid and suramin) and RB2 as a general $\mathrm{P} 2{ }_{\mathrm{Y}}$ receptor antagonist. Consistent with our previous observations (Rochon et al., 2001), there were no clear purinergic mechanisms that were identified in PSCs of either WT or SOD1 $1^{G 37 R}$ NMJs (data not shown). This suggests that, in the experimental conditions tested, activation of PSC purinergic contribution would be produced by other ATP-dependent mechanisms that still remain unidentified (Rochon et al., 2001).

Second, we examined the impact of mAChR blockade on nerve-evoked $\mathrm{Ca}^{2+}$ responses because they are the main receptor system through which PSCs are activated in adult NMJs (Rochon et al., 2001). Before testing the contribution of the PSC mAChR during synaptic transmission, we performed local application of agonists on PSC soma in the presence of the general mAChR antagonist atropine (5-20 $\mu \mathrm{M})$ applied in the bath. As shown in Figure $6 A, B$, the presence of atropine completely abolished $\mathrm{Ca}^{2+}$ responses elicited by muscarine in all cells tested $(N=4, n=10$ for WT mice and $N=4, n=8$ for $S O D 1^{G 37 R}$ mice) but did not prevent PSC $\mathrm{Ca}^{2+}$ responses elicited by local application of ATP on the same cells. This suggests that atropine was specific for PSC $\mathrm{mAChRs}$ and did not interfere with the ability of PSCs to produce large $\mathrm{Ca}^{2+}$ responses. This blockage was reversible because $\mathrm{Ca}^{2+}$ responses were elicited by muscarine application following 45 min of washout (data not shown; $N=3, n=3$ ).

Activation of PSCs during synaptic transmission is known to be blocked by atropine (Rochon et al., 2001). As shown in Figure $6 A, C, \mathrm{PSC} \mathrm{Ca}^{2+}$ responses of WT mice were significantly smaller in the presence of atropine $(22.2 \pm 2.8 \% \Delta \mathrm{F} / \mathrm{F}$ in atropine, $N=$ $10, n=15$ vs $34.3 \pm 4.3 \% \Delta \mathrm{F} / \mathrm{F}$ in control, $N=10, n=22$; unpaired $t$ test, $p=0.0433$ ). This represented a $35 \%$ contribution of the muscarinic signaling pathway during synaptic transmission. From all tested NMJs, 50\% of PSCs responded to motor nerveevoked release of neurotransmitters in the presence of atropine (15 of 30 PSCs). No significant difference was found in PSC Ca ${ }^{2+}$ responses in WT mice in association with Type I and Type IIa fiber types (Fig. $6 E$; MHC-I: $N=4, n=8$ for WT without atropine and $N=6, n=9$ for WT with atropine, unpaired $t$ test, $p=0.3661$; MHC-IIa: $N=7, n=12$ for WT without atropine and $N=4, n=6$ for WT with atropine, unpaired $t$ test, $p=0.1075$ ).

Similar to WT NMJs, blockage of $\mathrm{mAChR}$ with atropine on $S O D 1^{G 37 R}$ NMJs also reduced the amplitude of $\mathrm{Ca}^{2+}$ responses induced by nerve-evoked transmitter release (Fig. 6B). However, this reduction was much more pronounced than in the WT (atropine, $24.9 \pm 3.0 \% \Delta \mathrm{F} / \mathrm{F}, N=11, n=25$; control, $108.9 \pm$ $18.1 \% \Delta \mathrm{F} / \mathrm{F}, N=9, n=22$; unpaired $t$ test, $p<0.0001)$. This represented a $77 \%$ contribution of muscarinic signaling during 
A

WT

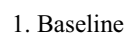

2. ATP

application
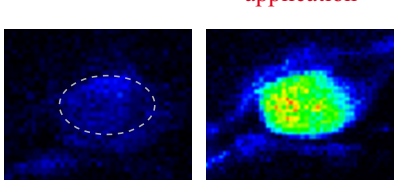

3. Recovery
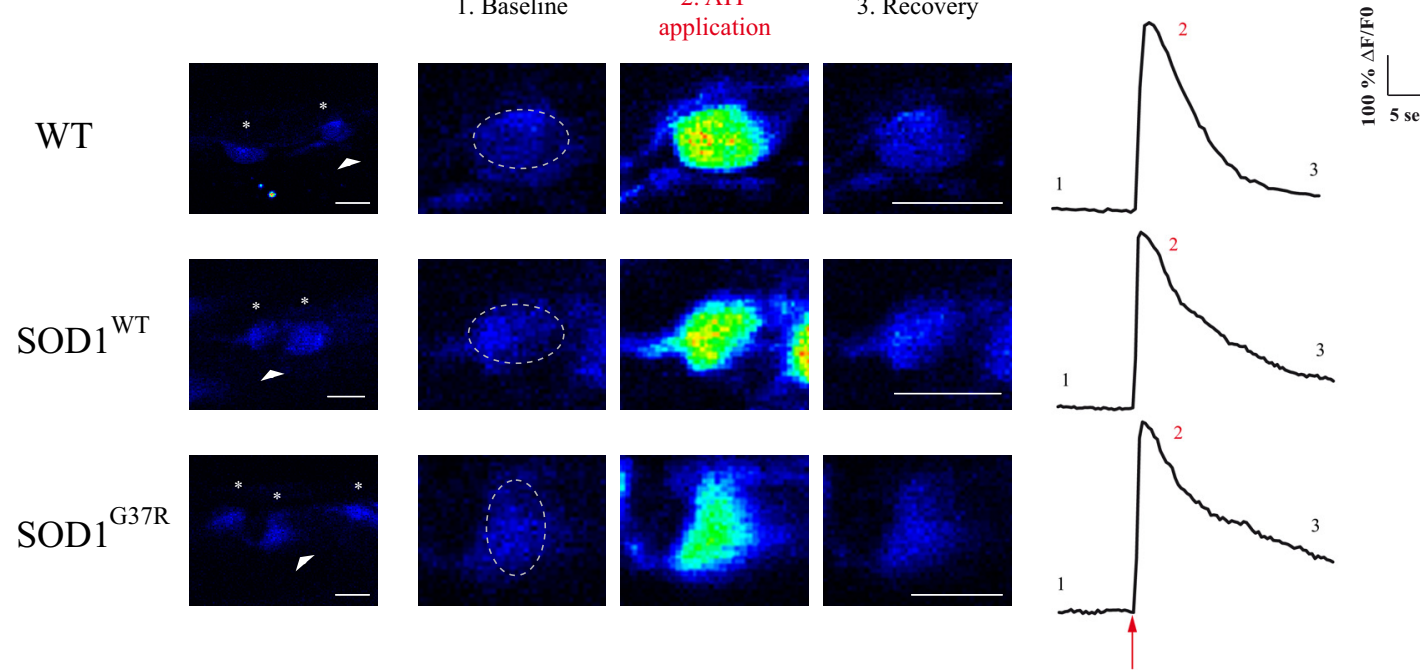

B

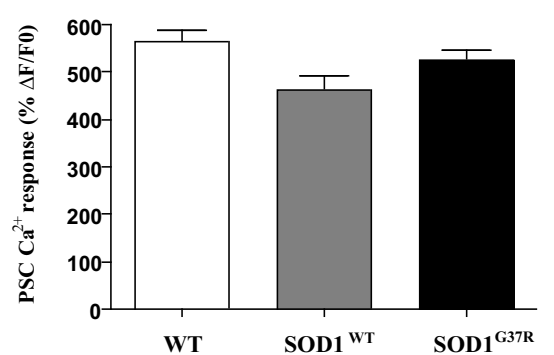

C
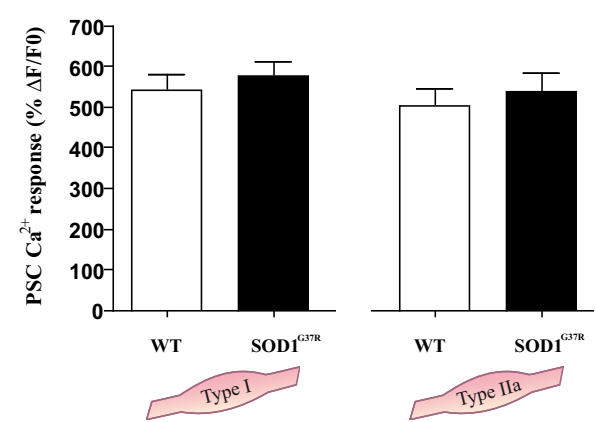

1. Baseline 2. Muscarine

D

WT
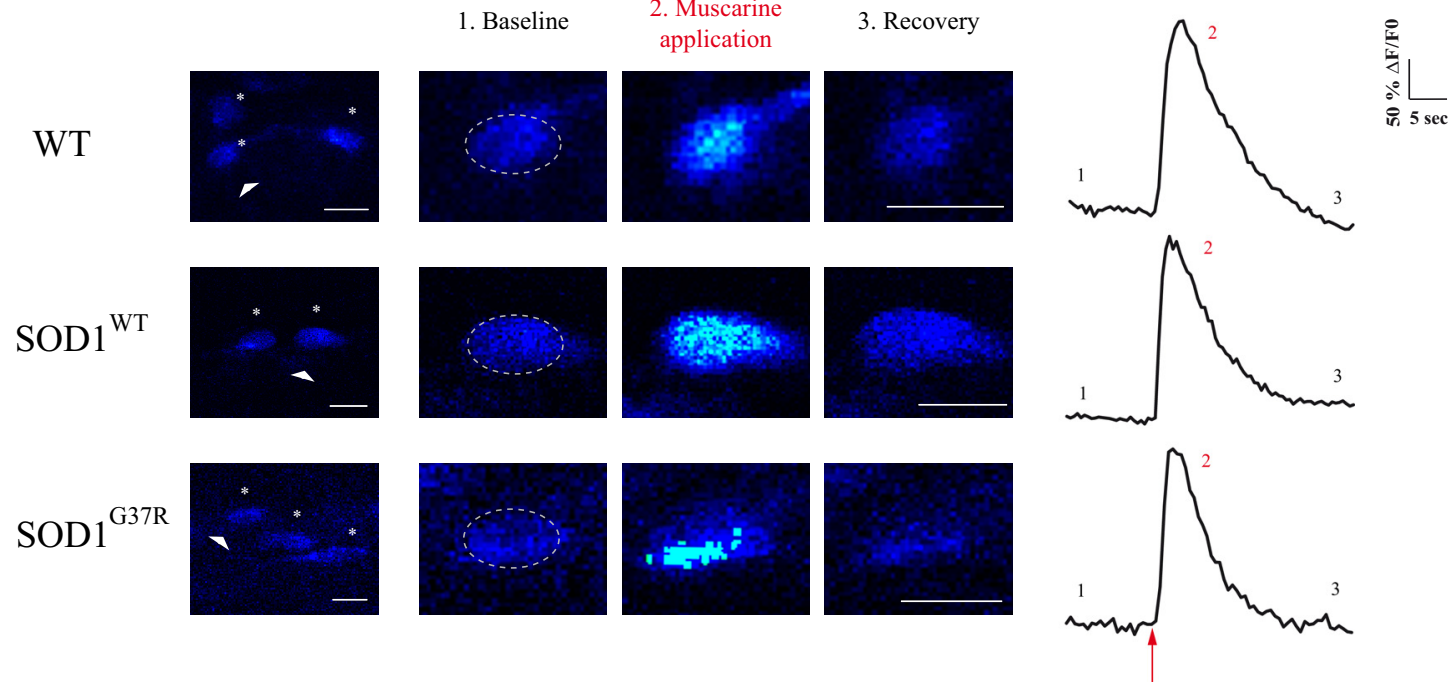

E

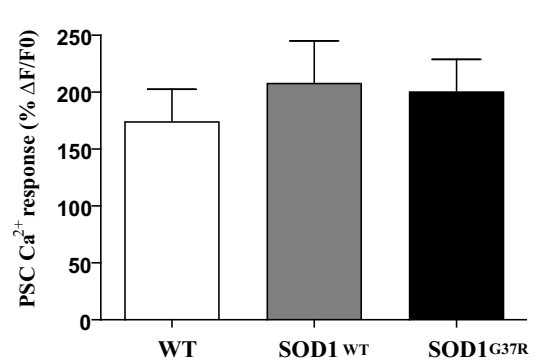

$\mathbf{F}$

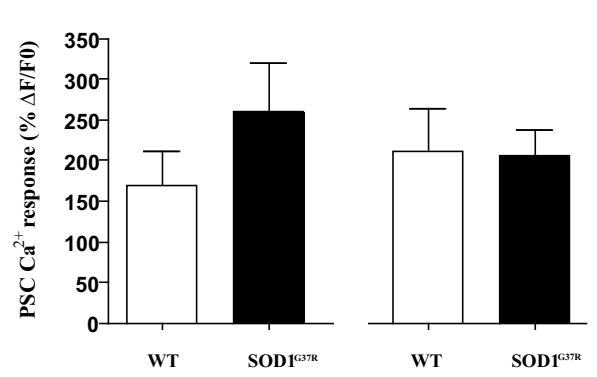

WT SOD1637R

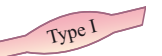


synaptic transmission. From all tested NMJs, 78\% of PSCs responded to neurotransmitter release in the presence of atropine ( 25 of 32 PSCs). Interestingly, the remaining amplitude of PSCs $\mathrm{Ca}^{2+}$ responses in the presence of atropine was comparable for WT and $S O D 1^{\text {G37R }}$ (Fig. 6C,D). Furthermore, because NMJ associated with fast fatigue-resistant $\mathrm{MN}$ and Type IIa fiber will degenerate first in the SOL during disease progression and PSC $\mathrm{mAChR}$ inactivation is required to repair the synapse, one would expect that PSC muscarinic contribution in these fibers to be lower than the one from fiber Type I. However, we found a significant difference between the average PSCs $\mathrm{Ca}^{2+}$ responses from $S O D 1^{G 37 R}$ mice with and without atropine associated with fiber Type I (3.7-fold) and fiber Type IIa (5.5-fold) (Fig. 6F; MHC-I: $N=4, n=9$ for SOD $1^{G 37 R}$ without atropine and $N=7$, $n=17$ for $S O D 1^{G 37 R}$ with atropine, unpaired $t$ test, $p=0.0013$; MHC-IIa: $N=4, n=8$ and for SOD $1^{G 37 R}$ with atropine and $N=$ $5, n=8$ for $S O D 1^{G 37 R}$ with atropine, unpaired $t$ test, $\left.p=0.0022\right)$.

As a whole, our data show that major synaptic alterations are already observed at an early stage of the disease (P120), particularly in Type I fibers, whereas PSCs show a muscarinic hyperactivation in both Type I and Type IIa fibers. Hence, these results reveal a larger contribution of PSC $\mathrm{mAChR}$ during synaptic communication in SOD $1^{G 37 R}$ mice that is independent of MN vulnerability at a presymptomatic stage of the disease. All these functional changes took place without any NMJ morphological alterations. These data suggest that ALS-associated events start long before symptom onset and involve several elements at the NMJ.

\section{Enhanced neurotransmitter release in $S O D 1^{G 37 R}$ mutants in the soleus muscle at P380}

To determine whether the observed alterations progress in the course of the disease or are simply transient, we further examined the properties of NMJ at an age close to the disease onset.

First, we evaluated the synaptic properties of $S O D 1^{G 37 R}$ mice at P380. We observed no difference in MEPP amplitude between WT and $S O D 1^{G 37 R}$ mice (WT, $0.27 \pm 0.01 \mathrm{mV}, N=7, n=21$; $S O D 1^{G 37 R}, 0.26 \pm 0.01 \mathrm{mV}, N=8, n=22$; unpaired $t$ test, $p=$ 0.2672; Fig. $7 A, B$ ). Surprisingly, unlike P120, no difference in MEPP frequency was observed in the SOL muscle of the $S O D 1^{G 37 R}$ mice at $\mathrm{P} 380$ where it was $0.88 \pm 0.12 \mathrm{~Hz}$ for the WT mice and $0.74 \pm 0.13 \mathrm{~Hz}$ for the $S O D 1^{G 37 R}$ mice (Fig. $7 \mathrm{~A}, C ; N=$ $6, n=17$ for WT and $N=7, n=15$ for $S O D 1^{G 37 R}$, unpaired $t$ test, $p=0.4601)$. Importantly, no difference in MEPP frequency and amplitude was observed between WT and $S O D 1^{G 37 R}$ mice in Type I fibers and Type IIa fibers (data not shown).

The properties of nerve-evoked synaptic activity of NMJs from mice at P380 were similar to the ones at P120 (stimulation at $0.2 \mathrm{~Hz}$ ) where amplitude of nerve-evoked EPPs in the SOD1 $1^{\text {G37R }}$ $(0.89 \pm 0.09 \mathrm{mV}, N=8, n=23)$ was significantly larger than WT

\section{$\leftarrow$}

Figure 5. $\mathrm{PSC} \mathrm{Ca}^{2+}$ responses to local application of ATP and muscarine. A, False color confocal images of PSCS $\left(^{*}\right)$ loaded with fluorescent $\mathrm{Ca}^{2+}$ indicator Fluo-4 AM, before (baseline), during (ATP application), and after (recovery) local ATP applications at NMJs of WT, $S O D 1^{W T}$, and $S O D 1^{G 37 R}$. Representative changes in fluorescence are illustrated on the right for the PSCs indicated by the arrowhead. Higher magnification of PSCs marked with the arrowhead in left are illustrated on the three other images for each group. $\boldsymbol{B}$, Histogram depicting the mean \pm SEM of the amplitude of the $\mathrm{Ca}^{2+}$ responses elicited in PSC by ATP application. $C$, Histograms depicting the mean \pm SEM of the amplitude of the $\mathrm{Ca}^{2+}$ responses elicited in PSC by ATP application as a function of fiber type. $\boldsymbol{D}-\boldsymbol{F}$, Similar representation as in $\boldsymbol{A}-\boldsymbol{C}$, but illustrating the muscarine application. There was no statistical difference between the different animal groups either for the ATP or the muscarine application (one-way ANOVA, $p>0.05$ ). Scale bar, $10 \mu \mathrm{m}$.
$(0.66 \pm 0.04 \mathrm{mV}, N=9, n=28)$ (Fig. $7 D, E$; unpaired $t$ test, $p=$ 0.0184). Importantly, a difference in EPP amplitude was observed between WT and SOD $1^{G 37 R}$ mice in Type I fibers (data not shown; $N=5, n=11,0.68 \pm 0.07 \mathrm{~Hz}$ for $\mathrm{WT}$ and $N=5, n=9$, $1.05 \pm 0.08 \mathrm{~Hz}$ for $S O D 1^{G 37 R}$, unpaired $t$ test, $p=0.0017$ ) but not in Type IIa fibers $(N=5, n=10,0.63 \pm 0.05 \mathrm{~Hz}$ for WT and $N=$ $5, n=6,0.62 \pm 0.03 \mathrm{~Hz}$ for $S O D 1^{G 37 R}$, unpaired $t$ test, $p=$ $0.8234)$.

Third, and consistent with these observations, quantal content of NMJs from SOD $1^{G 37 R}$ mice (3.45 $\left.\pm 0.29, N=8, n=22\right)$ was significantly higher compared with WT $(2.57 \pm 0.15, N=7$, $n=21$ ) (Fig. $7 F$; unpaired $t$ test, $p=0.0092$ ). Although the quantal content in Type I fibers was significantly higher in the $S O D 1^{G 37 R}$ than in the WT mice (data not shown; $N=5, n=9$, $2.85 \pm 0.20$ for WT and $N=5, n=9,3.97 \pm 0.31$ for $S O D 1^{G 37 R}$, unpaired $t$ test, $p=0.0084$ ), no difference was observed in Type IIa fibers (data not shown; $N=5, n=9,2.40 \pm 0.25$ for WT and $N=5, n=6,2.51 \pm 0.12$ for SOD1 ${ }^{G 37 R}$, unpaired $t$ test, $p=$ $0.7260)$. Again, similar to the P120 data, the SOD $1^{\text {G37R }}$ NMJs had a PPF value similar to the control group (Fig. 7G; WT, $1.31 \pm$ $0.02, N=9, n=28 ; S O D 1^{G 37 R}, 1.35 \pm 0.02, N=8, n=23$; unpaired $t$ test, $p=0.073$ ).

As a whole, electrophysiological data at a preonset age (P380) indicate that most synaptic properties observed very early on in the disease process were maintained throughout the nonsymptomatic phase of the disease.

\section{Excitability of PSCs remains altered just before the onset of the disease}

The ability of PSCs to detect and decode synaptic transmission is critical for their proper role in modulating synaptic function and maintenance (Ko and Robitaille, 2014). Hence, we evaluated whether the ability of PSCs to decode synaptic activity were altered at the preonset stage of the disease.

Using the same motor nerve stimulation ( $50 \mathrm{~Hz}$ for $5 \mathrm{~s}$ ), we observed that endogenous release of neurotransmitter induced $\mathrm{Ca}^{2+}$ responses in PSCs at NMJs of SOD1 ${ }^{G 37 R}$ mice (145.4 \pm $19.3 \% \Delta \mathrm{F} / \mathrm{F})$ that were significantly larger than in WT $(31.3 \pm$ $4.1 \% \Delta \mathrm{F} / \mathrm{F}$ (Fig. $8 A ; N=10, n=15$ for WT and $N=17, n=39$ for $S O D 1^{G 37 R}$, unpaired $t$ test, $\left.p=0.0006\right)$. These results indicate that PSCs at NMJs of an ALS mouse model still detected transmitter release at a preonset stage of the disease but with a persistent enhanced excitability and propensity to respond to synaptic activity (WT: $31 \%, 15$ of 48 PSCs activated; SOD $1^{\text {G37R }}: 51 \%, 39$ of 76 activated PSCs). PSC $\mathrm{Ca}^{2+}$ responses of WT and SOD1 mice were not different from the ones observed at P120 (unpaired $t$ test: for WT, $p=0.6320$ and for SOD $1^{G 37 R}, p=0.2155$ ).

We next tested whether PSC excitability reflected $\mathrm{MN}$ properties. As shown in Figure $8 B, C, \mathrm{Ca}^{2+}$ response amplitude from $S O D 1^{G 37 R}$ was 4.4- to 4.8-fold larger than WT for each fiber type (MHC-I: $N=6, n=9$ for WT and $N=5, n=17$ for $S O D 1^{G 37 R}$, unpaired $t$ test, $p=0.0098$ ) (MHC-IIa: $N=4, n=5$ for WT and $N=12, n=20$ for SOD $1^{G 37 R}$, unpaired $t$ test, $p=0.0413$ ). Together, again, these results suggest that alterations in PSC $\mathrm{Ca}^{2+}$ responses do not correlate with the predicted and specific vulnerability of MNs before the onset of the disease.

\section{Persistent alteration of the PSC muscarinic detection in mutant SOD1 mice}

Results described above showed that the muscarinic activation of PSCs was higher at NMJs of SOD1 mutant mice at an early stage of the disease. We wondered whether PSCs retained that property 
A

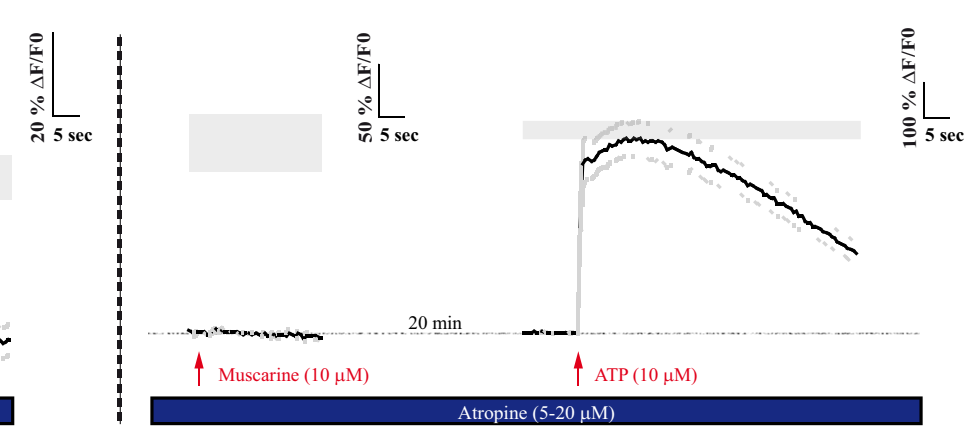

B

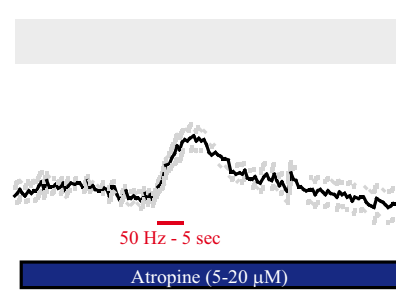

WT

SOD1 ${ }^{\mathrm{G} 37 \mathrm{R}}$
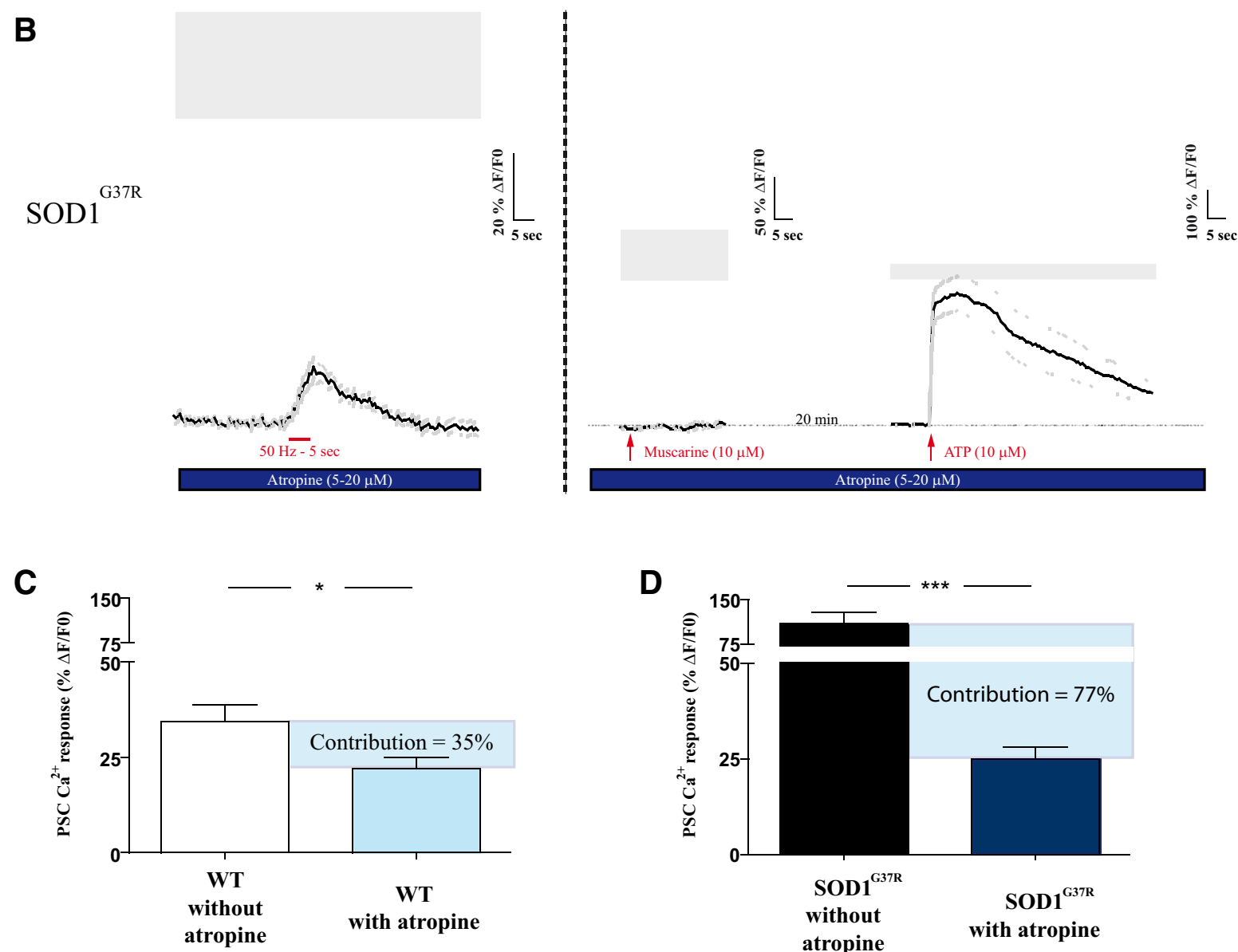

D

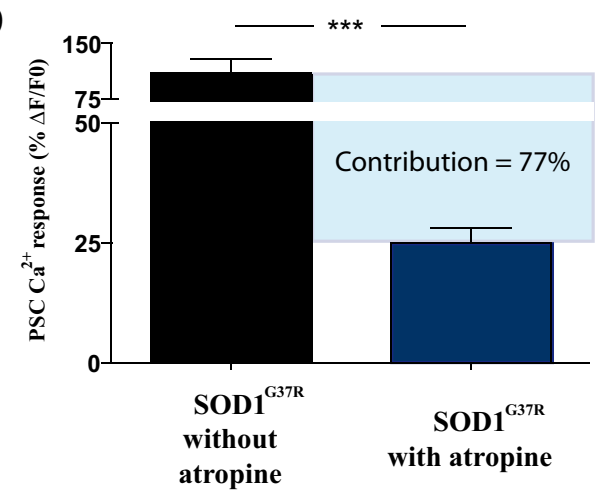

E
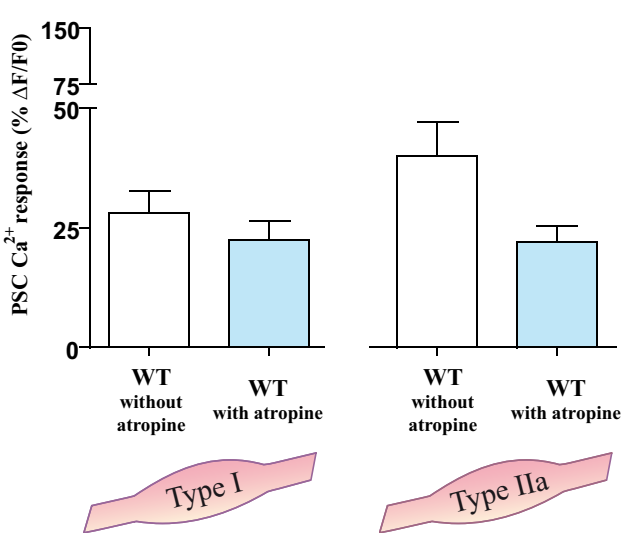

F

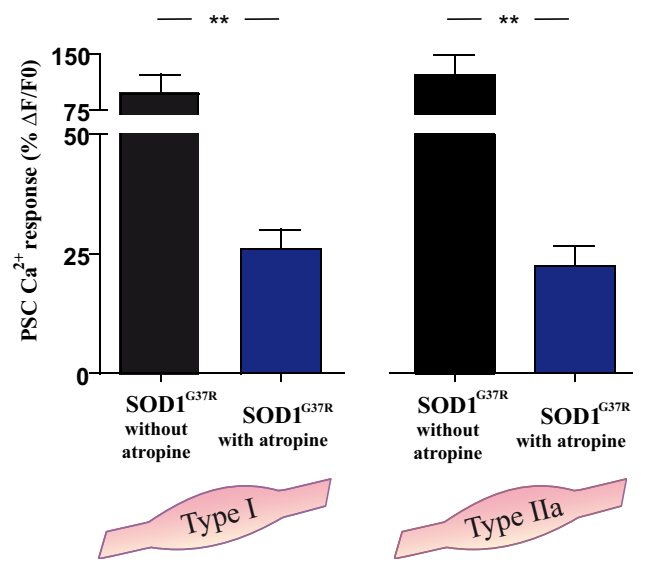


at preonset, a time when synaptic denervation becomes more prominent.

As shown in Figure 8A, PSC $\mathrm{Ca}^{2+}$ responses of WT mice were significantly smaller in the presence of atropine $(18.3 \pm 2.6 \%$ $\Delta \mathrm{F} / \mathrm{F}$ in atropine, $N=11, n=15$ vs $31.3 \pm 4.1 \% \Delta \mathrm{F} / \mathrm{F}$ in control, $N=10, n=15$; unpaired $t$ test, $p=0.0129$ ). This represents a $42 \%$ contribution of the muscarinic signaling pathway during synaptic transmission. From all tested NMJs, 37\% of PSCs responded to motor nerve-evoked release of neurotransmitters in the presence of atropine (15 of 41 PSCs). No significant difference was found in PSC $\mathrm{Ca}^{2+}$ responses in WT mice in association with Type I and Type IIa fiber types (Fig. $8 B$; MHC-I: $N=6, n=$ 9 for WT without atropine and $N=7, n=8$ for WT with atropine, unpaired $t$ test, $p=0.0998$; MHC-IIa: $N=4, n=5$ for WT without atropine and $N=5, n=7$ for WT with atropine, unpaired $t$ test, $p=0.0561$ ).

Similar to WT NMJs, blockage of mAChR with atropine on $S O D 1^{G 37 R}$ NMJs also reduced the amplitude of $\mathrm{Ca}^{2+}$ responses induced by nerve-evoked transmitter release (Fig. $8 A$ ). However, this reduction was much more pronounced than in the WT (atropine, $21.9 \pm 2.2 \% \Delta \mathrm{F} / \mathrm{F}, N=10, n=15$; control, $145.4 \pm$ $19.3 \% \Delta \mathrm{F} / \mathrm{F}, N=17, n=39$; unpaired $t$ test, $p=0.0016)$. This represents a $85 \%$ contribution of muscarinic signaling during synaptic transmission. From all tested NMJs, 36\% of PSCs responded to neurotransmitter release in the presence of atropine (15 of 42 PSCs). Again, we found a significant difference between the average PSC $\mathrm{Ca}^{2+}$ responses from SOD1 ${ }^{G 37 R}$ mice with and without atropine associated with fiber Type I (6.4-fold) and fiber Type IIa (7.4-fold) (Fig. 8C; MHC-I: $N=5, n=17$ for $S O D 1^{G 37 R}$ without atropine and $N=6, n=9$ for $S O D 1^{G 37 R}$ with atropine, unpaired $t$ test, $p=0.0061$; MHC-IIa: $N=12, n=20$ for $S O D 1^{G 37 R}$ without atropine and $N=5, n=6$ for $S O D 1^{G 37 R}$ with atropine, unpaired $t$ test, $p=0.0139$ ).

As a whole, these results reveal a larger contribution of PSC $\mathrm{mAChR}$ during synaptic communication in $S O D 1^{G 37 R}$ mice at $\mathrm{P} 380$, which remains independent of the known MN vulnerability.

\section{PSC ability to detect muscarinic signals is altered at P380}

PSC sensitivity to direct application of muscarinic and purinergic agonists was unaltered at P120. However, a fundamental prerequisite for PSCs to adapt their phenotype to the state of the NMJ (i.e., innervated vs denervated or mature vs immature) is to increase the sensitivity of the purinergic receptor signaling and lower the ones of the mAChRs (Darabid et al., 2013). We performed local applications of ATP and muscarine to test whether PSC sensitivity may be altered at a preonset period of the disease.

Local application of ATP $(10 \mu \mathrm{M})$ induced $\mathrm{Ca}^{2+}$ responses in $100 \%$ of PSCs with a mean of $576.1 \pm 38.7 \% \Delta \mathrm{F} / \mathrm{F}(N=8, n=$

$\leftarrow$

Figure 6. Larger contribution of $m A C h R$ activation of PSCs during synaptic transmission in SOD $7^{637 R}$ mice. PSC $\mathrm{Ca}^{2+}$ responses evoked by motor nerve stimulation in the presence of atropine $(5-20 \mu \mathrm{M})$ for WT $(\boldsymbol{A})$ and $\mathrm{SODD}^{\mathrm{G37R}}(\boldsymbol{B})$ mice. $\mathrm{No} \mathrm{Ca}^{2+}$ responses were elicited in PSCs by local application of muscarine in the presence of atropine while responses were still elicited by local application of ATP. Dark trace represents the average of PSC $\mathrm{Ca}^{2+}$ responses. Dotted line indicates the SEM. Gray boxes represent the mean \pm SEM of the amplitude of the $\mathrm{Ca}^{2+}$ responses elicited by nerve stimulation or agonist application without atropine. Histogram depicting the mean \pm SEM of the amplitude of the $\mathrm{Ca}^{2+}$ responses elicited in PSCs by transmitter release evoked by motor nerve stimulation $(50 \mathrm{~Hz}, 5 \mathrm{~s})$ during bath application of $\mathrm{mAChR}$ antagonist (atropine, 5-20 $\mu \mathrm{M}$ ) for WT $(\boldsymbol{C})$ and SOD $^{637 R}(\boldsymbol{D})$ mice. Histogram depicting the mean \pm SEM of the amplitude of the $\mathrm{Ca}^{2+}$ responses elicited in PSC by motor nerve stimulation in presence of atropine as a function of each fiber type for WT $(\boldsymbol{E})$ and $\operatorname{SOD}^{\mathrm{G}} 1^{\mathrm{G3R}}(\boldsymbol{F})$ mice. ${ }^{*} p<$ $0.05,{ }^{* *} p<0.01,{ }^{* * *} p<0.001$.
22) for the WT and $625.2 \pm 24.1 \% \Delta \mathrm{F} / \mathrm{F}(N=6, n=29)$ for $S O D 1^{G 37 R}$ (Fig. $9 A, B$; no significant difference, unpaired $t$ test, $p$ $=0.2649)$. Also, we found no significant difference in $\mathrm{Ca}^{2+}$ responses associated with Type I fibers (Fig. $9 C ; N=4, n=13$ for WT and $N=4, n=11$ for $S O D 1^{G 37 R}$, unpaired $t$ test, $p=0.3097$ ). Interestingly, we did find an increased $\mathrm{Ca}^{2+}$ responses in association with Type IIa fibers $(N=5, n=9$ for WT and $N=5, n=$ 18 for $S O D 1^{G 37 R}$, unpaired $t$ test, $\left.p=0.0012\right)$.

We next investigated the ability of a muscarinic agonist to evoke $\mathrm{Ca}^{2+}$ responses (Fig. 9D-F). Local application of muscarine $(10 \mu \mathrm{M})$ induced $\mathrm{Ca}^{2+}$ responses in $69.6 \%$ of PSCs of WT ( 32 of 46 PSCs) and $56.5 \%$ of PSCs for SOD $1^{\text {G37R }}$ ( 52 of 92 PSCs). Average of $\mathrm{Ca}^{2+}$ responses was $139.5 \pm 20.0 \% \Delta \mathrm{F} / \mathrm{F}(N=9, n=$ $32)$ for the WT and $248.6 \pm 21.5 \% \Delta \mathrm{F} / \mathrm{F}(N=10, n=52)$ for $S O D 1^{G 37 R}$ (Fig. 9D). These responses were statistically different (Fig. 9E; unpaired $t$ test, $p=0.0009$ ). Finally, we tested whether PSC detection reflected MN vulnerability. Similar to our observation with ATP activation, we found no significant difference between $\mathrm{Ca}^{2+}$ response amplitude from PSCs associated with Type I fibers for WT and SOD $1^{\text {G37R }}$ mice (Fig. 9F; $N=7, n=15$ for WT and $N=7, n=36$ for $S O D 1^{G 37 R}$, unpaired $t$ test, $p=$ $0.2339)$. However, we observed a significant increase in the amplitude of $\mathrm{Ca}^{2+}$ responses from PSCs associated with Type IIa fibers (Fig. 9F; $N=6, n=14$ for WT and $N=5, n=12$ for SOD $1^{\text {G37R }}$, unpaired $t$ test, $\left.p<0.0001\right)$.

Together, our results show that, close to symptom onset, NMJ synapses undergo persistent alterations of the synaptic functions whereby synaptic strength remains elevated only in Type I fibers, although spontaneous events are no longer enhanced. However, not only the glial alterations are maintained until the preonset in both fiber types, but an additional enhanced muscarinic sensitivity appeared in PSCs of Type IIa fibers.

As summarized in Figure 10, our results show that altered synaptic properties are maintained from an early, nonsymptomatic period, up to a preonset period. However, the glial alterations seem to correlate more with the disease progression. Indeed, PSC decoding abilities were unaltered at P60, whereas PSC excitability was enhanced at P120 through enhanced muscarinic activation. These features were maintained at P380, but an additional enhanced muscarinic contribution was unraveled only in Type IIa fibers, the ones that are more vulnerable to denervation.

As a whole, these results indicate that PSC phenotype is abnormal, with an imbalanced muscarinic and purinergic activation. As a consequence, the ability of PSCs to efficiently contribute to NMJ reinnervation could be impaired once the disease ultimately manifests itself, particularly in the more vulnerable fiber Type IIa.

\section{Discussion}

Using SOD $1^{G 37 R}$ mice, we report an inappropriate PSC decoding ability based on enhanced activation of $\mathrm{mAChRs}$ present early in the disease process (P120) and progressed until the preonset period of the disease (P380). Alteration of PSC $\mathrm{mAChR}$ functions is of particular importance because of their regulation of NMJ stability and repair. Our data suggest that the phenotype of PSCs is inconsistent with NMJ plasticity and repair, a condition that NMJs will necessarily undergo in ALS. To our knowledge, this is the earliest, persistent change reported in this mouse model (Ezzi et al., 2010; Filali et al., 2011). 


\section{A}
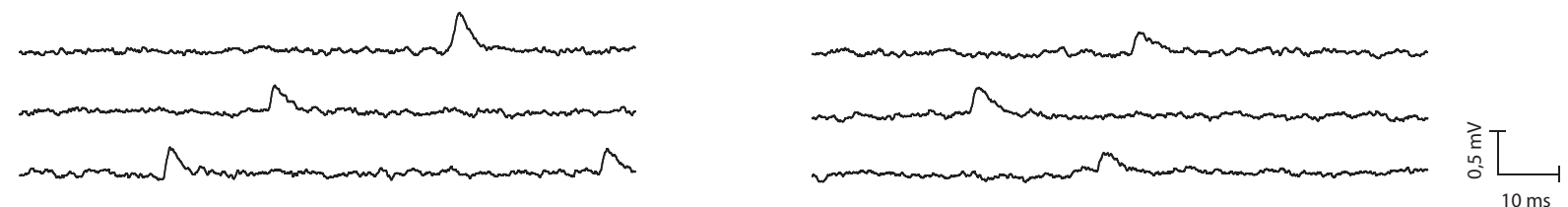

B

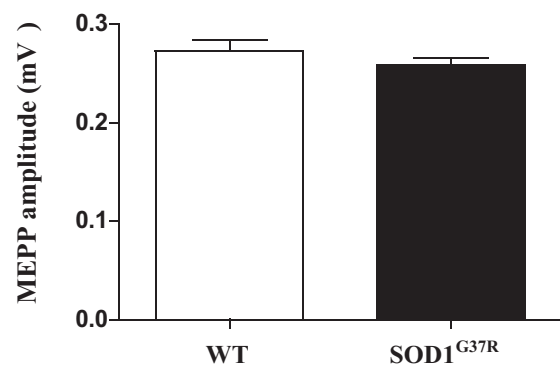

D

WT

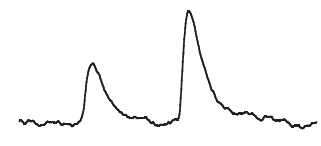

E

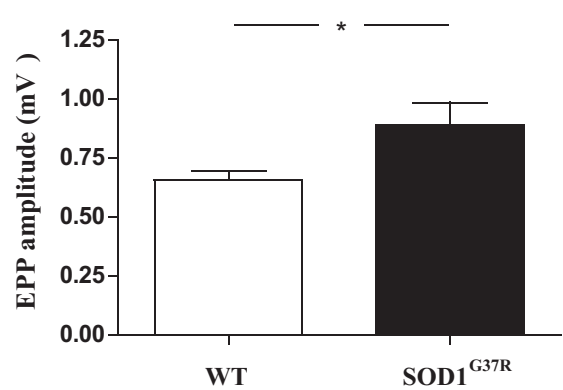

C

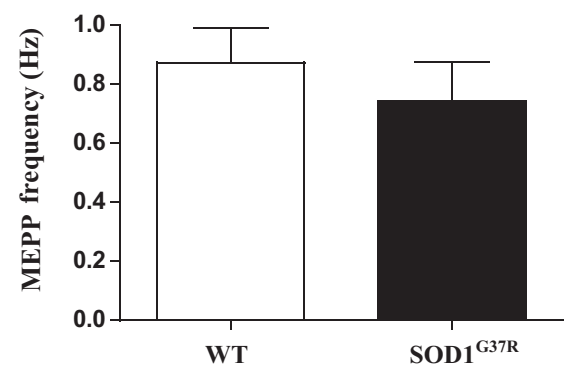

$\mathrm{SOD} 1^{\mathrm{G} 37 \mathrm{R}}$

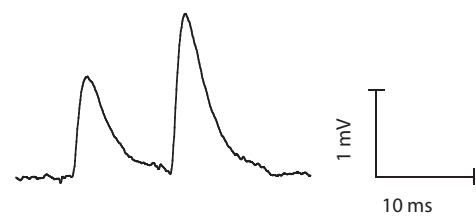

$\mathbf{F}$

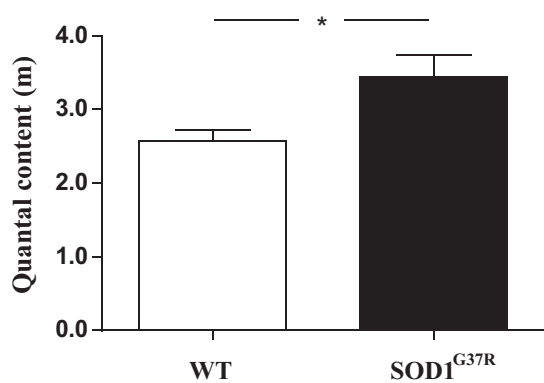

G

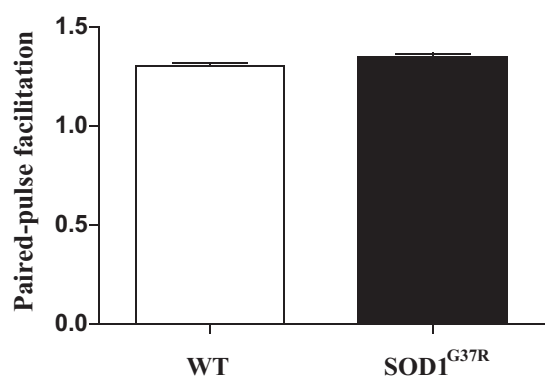

Figure 7. Enhanced synaptic transmission at NMJs from SOD $1^{G 37 R}$ mice at preonset stage of the disease. $\boldsymbol{A}$, Traces of spontaneous activity (MEPPS) recorded from WT and SOD ${ }^{G 37 R}$ NMJs. Histogram showing the mean \pm SEM of the amplitude $(\boldsymbol{B})$ and the frequency $(\boldsymbol{C})$ of MEPP events. $\boldsymbol{D}$, Examples of EPPs evoked by paired-pulse stimulation (10 ms interval) from WT and SOD1 $1^{G 37 R}$ NMJs. $\boldsymbol{E}$, Histogram showing the mean \pm SEM of the amplitude of the first EPP. $\boldsymbol{F}$, Histogram showing the quantal content determined as the ratio of EPP amplitude/mEPP amplitude. NMJs from $S O D 1^{G 37 R}$ mice had a larger quantal content. $\mathbf{G}$, Histogram showing the PPF determined as the mean amplitude of the second EPPs divided by the mean amplitude of the first EPPs. ${ }^{*} p<0.05$.

\section{Differential alteration of presynaptic and glial properties}

\section{in ALS}

The abnormal nerve-evoked synaptic properties remained throughout the adulthood life of the animal, which is particularly striking considering that SOL has a delayed degeneration in ALS (Frey et al., 2000; Atkin et al., 2005; Pun et al., 2006; Hegedus et al., 2007; Valdez et al., 2012). The abnormalities in the presynaptic functions in $S O D 1^{G 37 R}$ mice described here are consistent with the ones of the diaphragm preparation from $S O D 1^{\mathrm{G} 93 \mathrm{~A}}$ mice at a presymptomatic stage of the disease (Rocha et al., 2013), a muscle with the same fiber composition as the SOL (Zardini and Parry, 1994; Gregorevic et al.,
2008). Interestingly, others found that synaptic transmission was reduced at NMJs of fast twitch muscles of larval zebrafish carrying TDP-43 or FUS mutations (Armstrong and Drapeau, 2013a, b). Hence, it would be important to determine the properties of PSCs in a fast-twitch muscle knowing that PSCs at NMJs of different muscles have different properties (Rousse et al., 2010).

Similar to the hyperexcitability of mutant $S O D 1^{\mathrm{G} 93 \mathrm{~A}}$ spinal $\mathrm{MN}$ in culture and from organotypic slices (Pieri et al., 2003; Kuo et al., 2004), we observed an enhanced excitability and synaptic strength of the nerve terminal of SOD $1^{G 37 R}$. Interestingly, recent data suggest that the higher resilience to the disease of fast fatigue- 
A

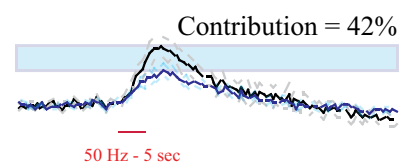

B

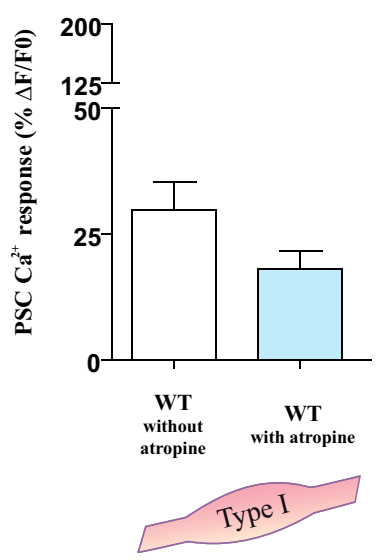

WT

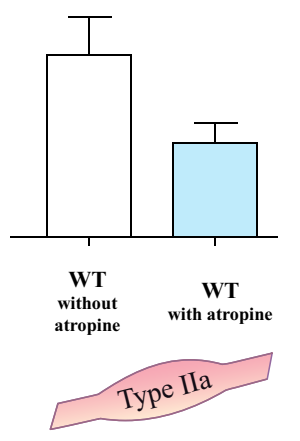

$\operatorname{SOD} 1^{\mathrm{G} 37 \mathrm{R}}$

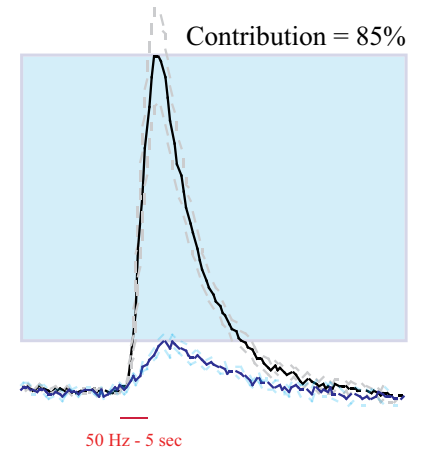

ì

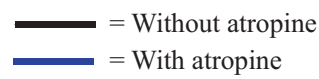

C

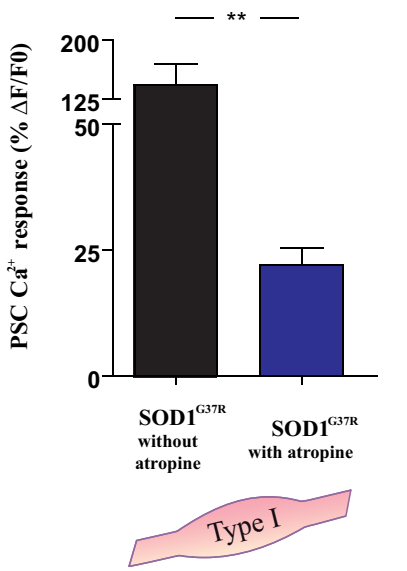

Figure 8. Altered PSC excitability at preonset stage of the disease. $A$, Dark traces represent the mean \pm SEM of the $\mathrm{Ca}^{2+}$ responses elicited in PSCs by transmitter release evoked by motor nerve stimulation $(50 \mathrm{~Hz}, 5 \mathrm{~s})$ at NMJs of WT and SOD $1^{637 R}$. Larger $\mathrm{Ca}^{2+}$ responses were elicited in PSCs of NMJs from SOD $1^{637 R}$ mice (unpaired $t$ test, $\left.p=0.0006\right)$. Blue traces represent the mean \pm SEM of the PSC nerve-evoked $(50 \mathrm{~Hz}, 5 \mathrm{~s}) \mathrm{Ca}^{2+}$ responses in presence of atropine $(20 \mu \mathrm{M})$ for WT and SOD $1^{637 R}$ mice. PSC $\mathrm{Ca}^{2+}$ responses of WT (unpaired t test, $\left.p=0.0129\right)$ and SOD1 mice (unpaired $t$ test, $p=0.0016$ ) were significantly smaller in the presence of atropine; this represents a $42 \%$ and $85 \%$ contribution of muscarinic signaling during synaptic transmission, respectively. $\boldsymbol{B}$, Histograms depicting the mean \pm SEM of the amplitude of the $\mathrm{Ca}^{2+}$ responses elicited in PSCs by motor nerve stimulation in the presence of atropine depending of each type of fiber for WT and

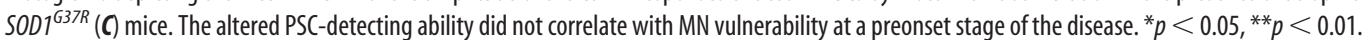

resistant and slow MNs is related to higher MN excitability (Saxena et al., 2013). Our results support this possibility because the quantal content of the slow $\mathrm{MN}$ alone (the more disease-resistant ones) was significantly higher in the $S O D 1^{G 37 R}$ mice. Furthermore, increased MEPP frequency at P120 has been observed in motor endplate disease, a hereditary disorder of NMJs caused by a progressive failure of neurotransmission (without denervation), muscle inactivity, and atrophy (Duchen and Stefani, 1971). Our data are also consistent with increased MEPP frequency (Uchitel et al., 1988; Appel et al., 1991) and quantal content at the mouse NMJ (O'Shaughnessy et al., 1998) induced by immunoglobulins from ALS patients. A common mechanism may be related to presynaptic $\mathrm{Ca}^{2+}$-dependent regulation (Uchitel et al., 1988; Appel et al., 1991; O’Shaughnessy et al., 1998; Armstrong and Drapeau, 2013a; Rocha et al., 2013) because of the larger $\mathrm{Ca}^{2+}$ accumulation in motor nerve terminals from ALS patients (Siklós et al., 1996) and the greater $\mathrm{Ca}^{2+}$ influx in nerve terminals that release more neurotransmitters (Pawson and Grinnell, 1990). However, the normal MEPP frequency observed at P380 is not consistent with this possibility, pointing to another molecular mechanism of exocytosis.

Unlike the abnormal synaptic properties, changes in PSC properties were first observed at P120 and evolved during the course of the disease. Indeed, PSC muscarinic and purinergic sensitivity increased with age in an MN vulnerability-dependent manner. Interestingly, similar to neurons, PSCs undergo plastic changes following an alteration of synaptic activity (Bélair et al., 2010), resulting in changes of receptor contribution and sensitivity. For instance, PSC purinergic receptor contribution is increased and the muscarinic one decreased in conditions when morphological plasticity is required, such as NMJ maturation (Darabid et al., 2013) and after nerve injury (Georgiou et al., 1999, 1994, Perez and Robitaille, personal communication).

Interestingly, there is an important mismatch between the synaptic and the PSC properties of NMJs on Type I and Type IIa MNs. Indeed, although synaptic output was only higher for Type I MNs, PSCs muscarinic excitability was high in both types. Although this glial feature would help maintain NMJs during ALS pathogenesis and be consistent with the stability of the Type I NMJs, it appears detrimental for the Type IIa. Indeed, permissiveness of PSCs for NMJ repair requires a reduced muscarinic receptor activity (Darabid et al., 2014). However, although Type IIa MNs are targeted before Type I, PSCs at these NMJs still present a high muscarinic sensitivity close to the disease onset. Hence, this imbalance of PSC receptors appears as a limiting factor for NMJ repair in ALS.

Overall, our data indicate that the synaptic properties are present early and appear maintained until the disease onset, 
A

WT

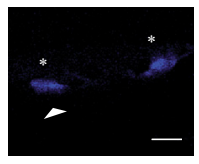

1. Baseline
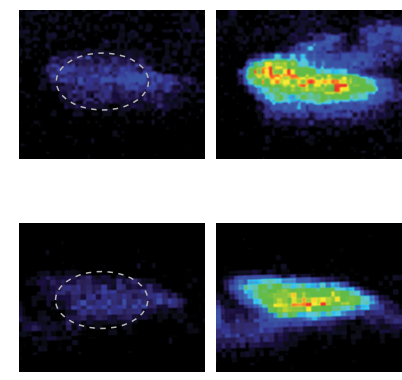

2. ATP

application
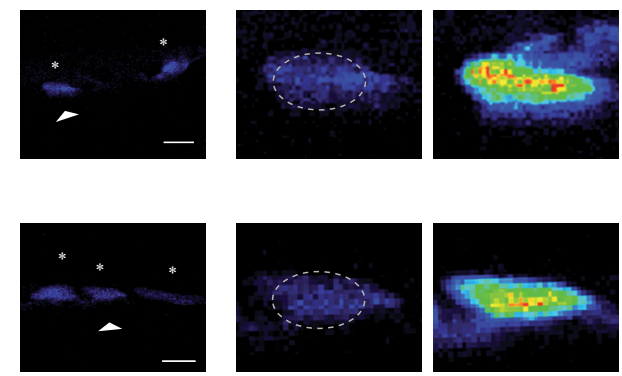

B

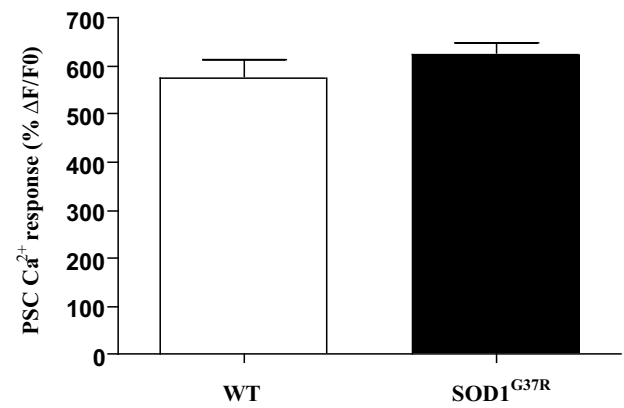

3. Recovery
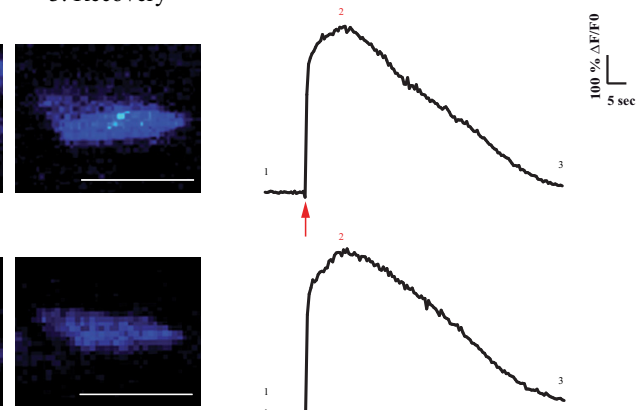

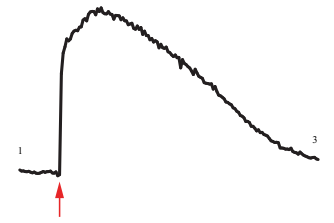

C

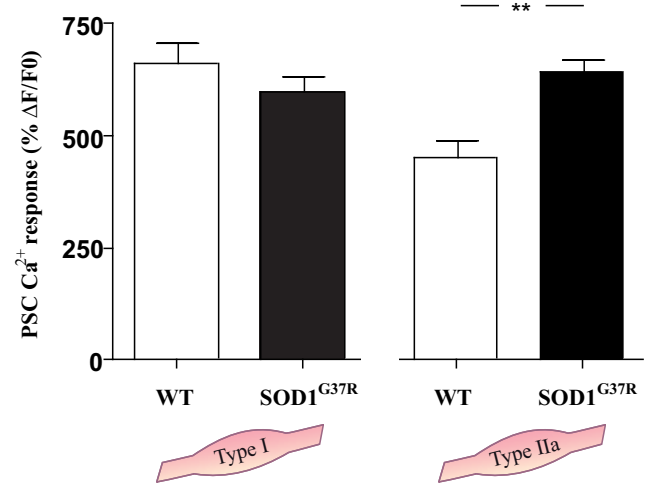

D

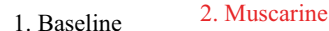
application

WT
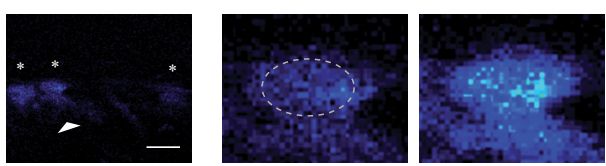

3. Recovery
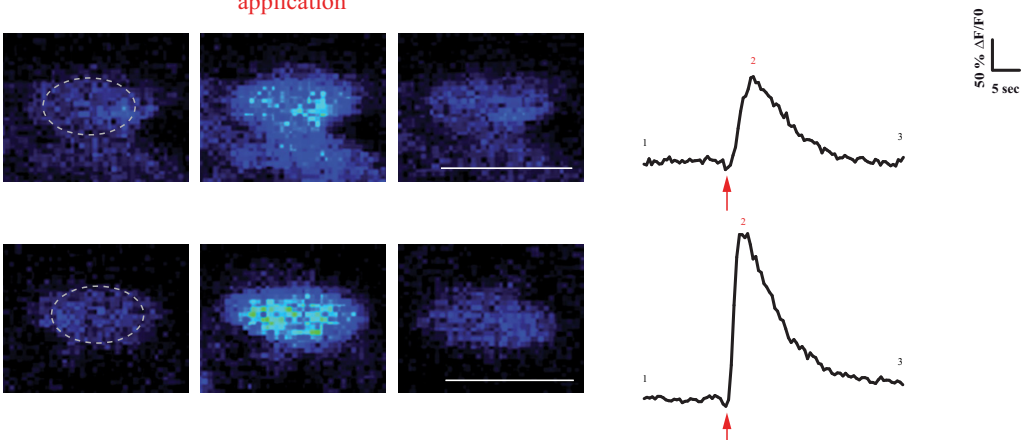

$\mathbf{E}$
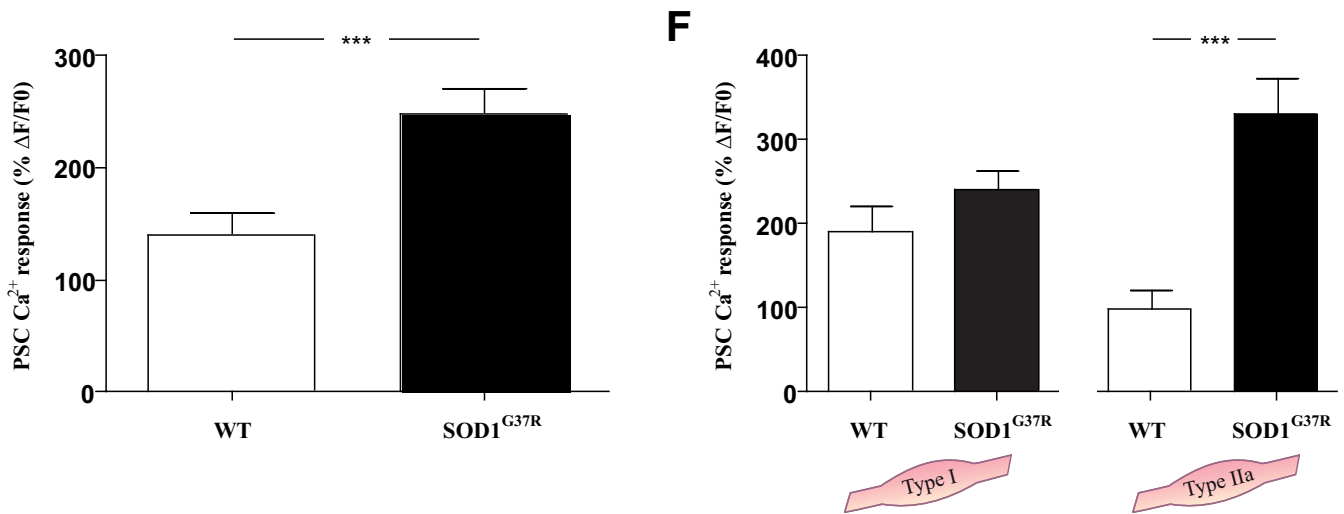

Figure 9. PSC Ca ${ }^{2+}$ responses to local application of ATP and muscarine at preonset stage of the disease. $A$, False color confocal images of PSCs $\left({ }^{*}\right)$ loaded with fluorescent $\mathrm{Ca}{ }^{2+}$ indicator Fluo-4 AM, before (baseline), during (ATPapplication), and after (recovery) local ATPapplications atNMUs ofWT and SOD1 ${ }^{637 R}$. Representativechanges influorescenceareillustrated on therightforthePSCsindicated by thearrowhead. Highermagnification of PSCs marked with the arrowhead in left are illustrated on the three other images for each group. $\boldsymbol{B}$, Histogram depicting the mean \pm SEM of the amplitude of the $\mathrm{Ca}^{2+}$ responses elicited in PSCs by ATP application. $\boldsymbol{C}$, Histograms depicting the mean \pm SEM of the amplitude of the $\mathrm{Ca}^{2+}$ responses elicited in PSC by ATP as a function of each fiber type. $\boldsymbol{D}-\boldsymbol{F}$, Similar representation as in $\boldsymbol{A}-\boldsymbol{C}$, but for muscarine application. Note the statistical difference between the different animal groups for the muscarine application and for the $\mathrm{PSCCa}^{2+}$ responses associated with fiber Type lla for ATP and muscarine application. Scale bar, $10 \mu \mathrm{m}$. ${ }^{* * *} p<0.001$. 


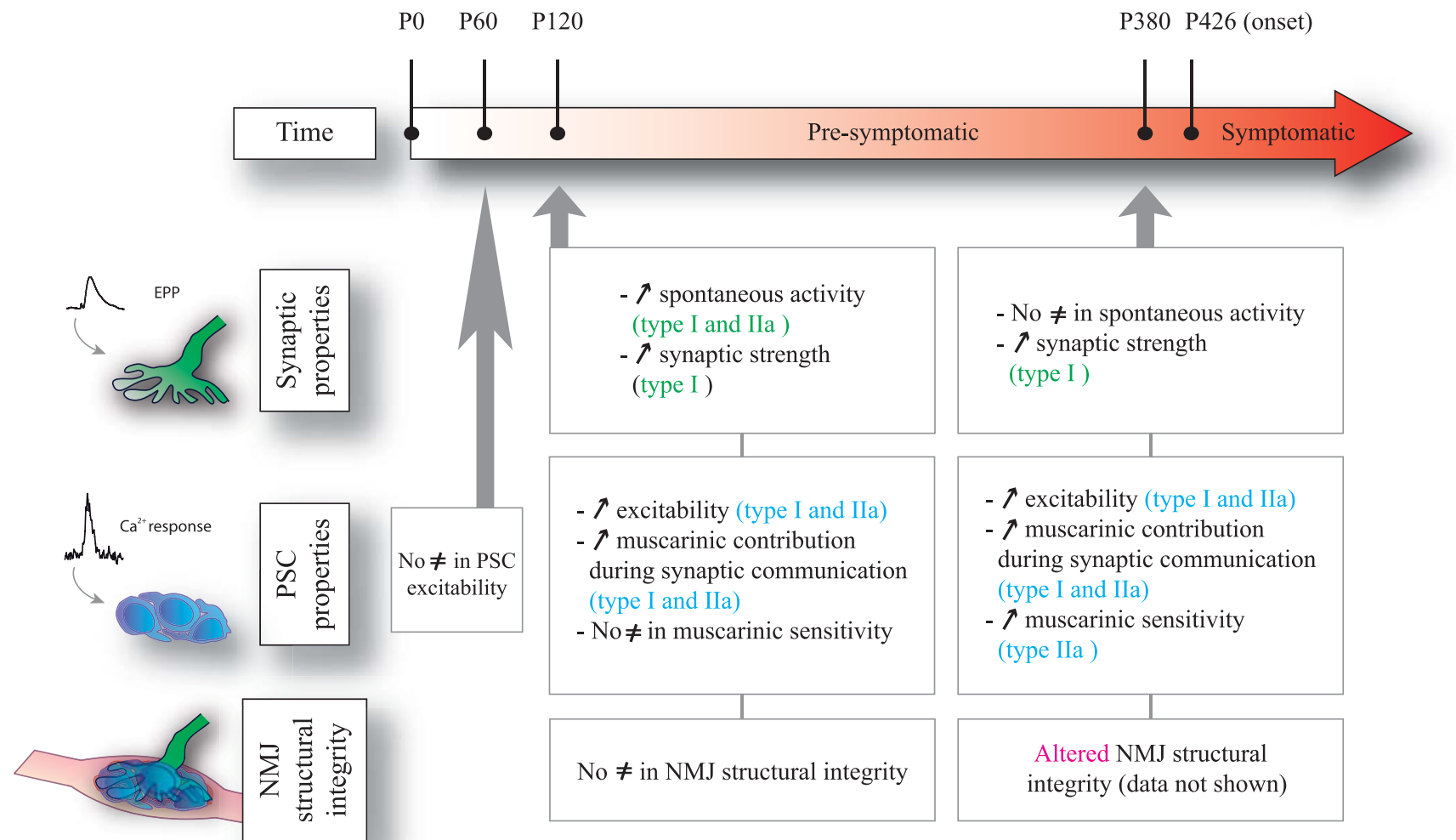

Figure 10. Timeline of changes in NMJ structure and function at presymptomatic stages of the disease in SOL muscle. Summary of the changes in the presynaptic properties (top), PSC properties (middle), and the morphological features (bottom) is presented as a function of the age of the animals. It shows that synaptic properties are observed early and only in Type I fibers and maintained throughout. However, PSC properties are altered in both fiber types and further evolve at a presymptomatic stage. Morphological features are normal at P120 but altered at the presymptomatic stage. $\uparrow$ indicates a significant increase in SOD1 compared with WT, and "No $\neq$ " indicates that there was no statistical difference.

whereas PSC properties gradually evolve and worsen toward disease onset. In addition, our data indicate that functional changes in synaptic and glial activities are more sensitive indicators of the state of NMJ functions in ALS than are the morphological characteristics, the former appearing several months before the latter. Hence, it would be important to develop tools to measure these properties, providing a more sensitive readout of the NMJ functions and an earlier detection of NMJ dysfunctions.

\section{Impact of PSC abnormalities in ALS}

The roles of axonal Schwann cells in ALS were studied using selective expression or knock-out of mutant SOD1 in these cells (Lobsiger et al., 2009; Turner et al., 2010; Wang et al., 2012). However, these studies were not designed to specifically assess PSC contributions in ALS pathogenesis. This is important considering that PSCs are quite different from axonal Schwann cells based on their properties and functions at the NMJ (Auld and Robitaille, 2003).

Implication of glial cells at the NMJ in ALS remains ill-defined, although the involvement of glial cells in MN death has received strong support and selective rescue of $\mathrm{MN}$ death only modestly delayed denervation and improved lifespan (Gould et al., 2006). An interesting possibility is that the adverse relationship between glial cells and MNs in the spinal cord in ALS may be replicated at the NMJ (Carrasco et al., 2010). Indeed, using whole-muscle transplants in $S O D 1^{\mathrm{G} 93 \mathrm{~A}}$ mice, Carrasco et al. (2010) hypothesized that the properties of nerve terminal and PSCs, and not the muscle transplant, were determinant for the degenerative changes observed at the NMJ. This suggests that interactions between PSCs and motor nerve ter- minal are crucial to understand how the degenerative changes begin and progress at NMJs in ALS.

Detrimental consequences for the stability and repair of the NMJ in ALS may emerge from the altered PSC decoding ability and mAChR sensitivity. For instance, the larger activation of PSC mAChR during synaptic transmission at P120 and P380 in SOD1 mutants implies that their detection threshold is decreased, which could maintain their muscarinic activation even in conditions of reduced synaptic activity. This would maintain gene expression compatible with NMJ maintenance, preventing PSCs to switch to the repair phenotype needed when denervation occurs. One possibility is that the formation and/or extension of PSC processes may be altered. However, our observations and those of others (Frey et al., 2000; Gould et al., 2006) argue against this suggestion because PSC processes have been observed in ALS mouse models. Another interesting possibility is that the guidance of the motor nerve terminal and the remodeling/stabilization of the new synapse may be altered (Kang et al., 2014). An altered propensity to repair and reform NMJs following nerve injury in ALS models supports this possibility (Gordon et al., 2004). Furthermore, the clearance of debris (Kang and Lichtman, 2013) and lack of metabolic support can also be involved (Moloney et al., 2014). Hence, we postulate that the inadequate muscarinic activation of PSCs leads to an improper repair of NMJ structure and function during the course of the disease.

\section{Potential mechanisms underlying an increased muscarinic excitability}

The inadequate $\mathrm{mAChR}$ activation of PSC may have several origins. The distribution and density of the mAChRs on PSC pro- 
cesses close to active zones and/or changes in the functionality of the receptor per se can be altered. Other mechanisms may include changes in the receptor subtypes on PSC (M1, M3 and M5) (Wright et al., 2009; Darabid et al., 2013), affinity, insertion, and recycling or their association with internal molecular machinery activating different downstream signaling pathways.

Another interesting mechanism is that the soluble SOD $1^{G 37 R}$ protein impacts on $\mathrm{mAChR}$ functionality. Indeed, it was suggested that soluble SOD1 protein interacts with cellular membrane and alter muscarinic receptor activation of phospholipase C pathway (Damiano et al., 2013).

In conclusion, because of their roles in regulating the balance between synaptic efficacy, maintenance, and repair following injury, the enhanced mAChR activation of PSCs would impinge the quality and reliability of NMJ repair during ALS progression. Future demonstration of this PSC malfunction as a potential contributor to ALS and also in other ALS models (e.g., TDP-43 and/or FUS) will highlight the importance and broad implication of such mechanisms. Our study is the first direct evidence of glial alteration at the NMJ despite the importance of NMJ malfunction and the reported involvement of other glial cells in ALS. The intrinsic PSC properties could represent a very important and novel therapeutic target in ALS.

\section{References}

Amendola J, Gueritaud JP, Lamotte d'Incamps B, Bories C, Liabeuf S, Allene C, Pambo-Pambo A, Durand J (2007) Postnatal electrical and morphological abnormalities in lumbar motoneurons from transgenic mouse models of amyotrophic lateral sclerosis. Arch Ital Biol 145:311-323. Medline

Appel SH, Engelhardt JI, García J, Stefani E (1991) Immunoglobulins from animal models of motor neuron disease and from human amyotrophic lateral sclerosis patients passively transfer physiological abnormalities to the neuromuscular junction. Proc Natl Acad Sci U S A 88:647-651. CrossRef Medline

Armstrong GA, Drapeau P (2013a) Calcium channel agonists protect against neuromuscular dysfunction in a genetic model of TDP-43 mutation in ALS. J Neurosci 33:1741-1752. CrossRef Medline

Armstrong GA, Drapeau P (2013b) Loss and gain of FUS function impair neuromuscular synaptic transmission in a genetic model of ALS. Hum Mol Genet 22:4282-4292. CrossRef Medline

Atkin JD, Scott RL, West JM, Lopes E, Quah AK, Cheema SS (2005) Properties of slow- and fast-twitch muscle fibres in a mouse model of amyotrophic lateral sclerosis. Neuromuscul Disord 15:377-388. CrossRef Medline

Audet JN, Gowing G, Julien JP (2010) Wild-type human SOD1 overexpression does not accelerate motor neuron disease in mice expressing murine Sod1 G86R. Neurobiol Dis 40:245-250. CrossRef Medline

Auld DS, Robitaille R (2003) Perisynaptic Schwann cells at the neuromuscular junction: nerve- and activity-dependent contributions to synaptic efficacy, plasticity, and reinnervation. Neuroscientist 9:144-157. CrossRef Medline

Bélair EL, Vallée J, Robitaille R (2010) In vivo long-term synaptic plasticity of glial cells. J Physiol 588:1039-1056. CrossRef Medline

Boillée S, Yamanaka K, Lobsiger CS, Copeland NG, Jenkins NA, Kassiotis G, Kollias G, Cleveland DW (2006) Onset and progression in inherited ALS determined by motor neurons and microglia. Science 312:13891392. CrossRef Medline

Bories C, Amendola J, Lamotte d'Incamps B, Durand J (2007) Early electrophysiological abnormalities in lumbar motoneurons in a transgenic mouse model of amyotrophic lateral sclerosis. Eur J Neurosci 25:451459. CrossRef Medline

Carrasco DI, Bichler EK, Seburn KL, Pinter MJ (2010) Nerve terminal degeneration is independent of muscle fiber genotype in SOD1 mice. PLoS One 5:e9802. CrossRef Medline

Chipman PH, Franz CK, Nelson A, Schachner M, Rafuse VF (2010) Neural cell adhesion molecule is required for stability of reinnervated neuromuscular junctions. Eur J Neurosci 31:238-249. CrossRef Medline

Clement AM, Nguyen MD, Roberts EA, Garcia ML, Boillée S, Rule M, McMahon AP, Doucette W, Siwek D, Ferrante RJ, Brown RH Jr, Julien JP, Goldstein LS, Cleveland DW (2003) Wild-type nonneuronal cells ex- tend survival of SOD1 mutant motor neurons in ALS mice. Science 302: 113-117. CrossRef Medline

Colomar A, Robitaille R (2004) Glial modulation of synaptic transmission at the neuromuscular junction. Glia 47:284-289. CrossRef Medline

Damiano S, Petrozziello T, Ucci V, Amente S, Santillo M, Mondola P (2013) $\mathrm{Cu}-\mathrm{Zn}$ superoxide dismutase activates muscarinic acetylcholine M1 receptor pathway in neuroblastoma cells. Mol Cell Neurosci 52:31-37. CrossRef Medline

Darabid H, Arbour D, Robitaille R (2013) Glial cells decipher synaptic competition at the mammalian neuromuscular junction. J Neurosci 33:12971313. CrossRef Medline

Darabid H, Perez-Gonzalez AP, Robitaille R (2014) Neuromuscular synaptogenesis: coordinating partners with multiple functions. Nat Rev Neurosci Advanced online publication. Retrieved Oct. 1, 2014; doi: 10.1038/nrn3821.

Del Castillo J, Katz B (1954) Quantal components of the end-plate potential. J Physiol 124:560-573. Medline

Delestrée N, Manuel M, Iglesias C, Elbasiouny SM, Heckman CJ, Zytnicki D (2014) Adult spinal motoneurones are not hyperexcitable in a mouse model of inherited amyotrophic lateral sclerosis. J Physiol 592:16871703. CrossRef Medline

Duchen LW, Stefani E (1971) Electrophysiological studies of neuromuscular transmission in hereditary 'motor end-plate disease' of the mouse. J Physiol 212:535-548. Medline

Dupuis L, Loeffler JP (2009) Neuromuscular junction destruction during amyotrophic lateral sclerosis: insights from transgenic models. Curr Opin Pharmacol 9:341-346. CrossRef Medline

Ezzi SA, Larivière R, Urushitani M, Julien JP (2010) Neuronal overexpression of chromogranin A accelerates disease onset in a mouse model of ALS. J Neurochem 115:1102-1111. CrossRef Medline

Feng Z, Ko CP (2008) The role of glial cells in the formation and maintenance of the neuromuscular junction. Ann N Y Acad Sci 1132:19-28. CrossRef Medline

Filali M, Lalonde R, Rivest S (2011) Sensorimotor and cognitive functions in a SOD1(G37R) transgenic mouse model of amyotrophic lateral sclerosis. Behav Brain Res 225:215-221. CrossRef Medline

Fischer LR, Culver DG, Tennant P, Davis AA, Wang M, Castellano-Sanchez A, Khan J, Polak MA, Glass JD (2004) Amyotrophic lateral sclerosis is a distal axonopathy: evidence in mice and man. Exp Neurol 185:232-240. CrossRef Medline

Frey D, Schneider C, Xu L, Borg J, Spooren W, Caroni P (2000) Early and selective loss of neuromuscular synapse subtypes with low sprouting competence in motoneuron diseases. J Neurosci 20:2534-2542. Medline

Georgiou J, Robitaille R, Trimble WS, Charlton MP (1994) Synaptic regulation of glial protein expression in vivo. Neuron 12:443-455. CrossRef Medline

Georgiou J, Robitaille R, Charlton MP (1999) Muscarinic control of cytoskeleton in perisynaptic glia. J Neurosci 19:3836-3846. Medline

Gordon T, Hegedus J, Tam SL (2004) Adaptive and maladaptive motor axonal sprouting in aging and motoneuron disease. Neurol Res 26:174-185. CrossRef Medline

Gould TW, Buss RR, Vinsant S, Prevette D, Sun W, Knudson CM, Milligan CE, Oppenheim RW (2006) Complete dissociation of motor neuron death from motor dysfunction by Bax deletion in a mouse model of ALS. J Neurosci 26:8774-8786. CrossRef Medline

Gregorevic P, Meznarich NA, Blankinship MJ, Crawford RW, Chamberlain JS (2008) Fluorophore-labeled myosin-specific antibodies simplify muscle-fiber phenotyping. Muscle Nerve 37:104-106. CrossRef Medline

Hegedus J, Putman CT, Gordon T (2007) Time course of preferential motor unit loss in the SOD1 G93A mouse model of amyotrophic lateral sclerosis. Neurobiol Dis 28:154-164. CrossRef Medline

Hegedus J, Putman CT, Tyreman N, Gordon T (2008) Preferential motor unit loss in the SOD1 G93A transgenic mouse model of amyotrophic lateral sclerosis. J Physiol 586:3337-3351. CrossRef Medline

Jahromi BS, Robitaille R, Charlton MP (1992) Transmitter release increases intracellular calcium in perisynaptic Schwann cells in situ. Neuron 8:1069-1077. CrossRef Medline

Kang H, Lichtman JW (2013) Motor axon regeneration and muscle reinnervation in young adult and aged animals. J Neurosci 33:19480-19491. CrossRef Medline

Kang H, Tian L, Mikesh M, Lichtman JW, Thompson WJ (2014) Terminal Schwann cells participate in neuromuscular synapse remodeling during 
reinnervation following nerve injury. J Neurosci 34:6323-6333. CrossRef Medline

Kang SH, Li Y, Fukaya M, Lorenzini I, Cleveland DW, Ostrow LW, Rothstein JD, Bergles DE (2013) Degeneration and impaired regeneration of gray matter oligodendrocytes in amyotrophic lateral sclerosis. Nat Neurosci 16:571-579. CrossRef Medline

Keller AF, Gravel M, Kriz J (2009) Live imaging of amyotrophic lateral sclerosis pathogenesis: disease onset is characterized by marked induction of GFAP in Schwann cells. Glia 57:1130-1142. CrossRef Medline

Ko CP, Robitaille R (2014) Perisynaptic Schwann cells at the neuromuscular synapse: adaptable, multitasking glial cells (Barres, Freeman, Stevens, eds). Cold Spring Harbor, NY: Cold Spring Harbor Press.

Kuo JJ, Schonewille M, Siddique T, Schults AN, Fu R, Bär PR, Anelli R, Heckman CJ, Kroese AB (2004) Hyperexcitability of cultured spinal motoneurons from presymptomatic ALS mice. J Neurophysiol 91:571575. CrossRef Medline

Lobsiger CS, Boillée S, McAlonis-Downes M, Khan AM, Feltri ML, Yamanaka K, Cleveland DW (2009) Schwann cells expressing dismutase active mutant SOD1 unexpectedly slow disease progression in ALS mice. Proc Natl Acad Sci U S A 106:4465-4470. CrossRef Medline

Mallart A, Martin AR (1968) The relation between quantum content and facilitation at the neuromuscular junction of the frog. J Physiol 196:593604. Medline

Moloney EB, de Winter F, Verhaagen J (2014) ALS as a distal axonopathy: molecular mechanisms affecting neuromuscular junction stability in the presymptomatic stages of the disease. Front Neurosci 8:252. CrossRef Medline

O’Malley JP, Waran MT, Balice-Gordon RJ (1999) In vivo observations of terminal Schwann cells at normal, denervated, and reinnervated mouse neuromuscular junctions. J Neurobiol 38:270-286. CrossRef Medline

O'Shaughnessy TJ, Yan H, Kim J, Middlekauff EH, Lee KW, Phillips LH, Kim J, Kim YI (1998) Amyotrophic lateral sclerosis: serum factors enhance spontaneous and evoked transmitter release at the neuromuscular junction. Muscle Nerve 21:81-90. CrossRef Medline

Pawson PA, Grinnell AD (1990) Physiological differences between strong and weak frog neuromuscular junctions: a study involving tetanic and posttetanic potentiation. J Neurosci 10:1769-1778. Medline

Pieri M, Albo F, Gaetti C, Spalloni A, Bengtson CP, Longone P, Cavalcanti S, Zona C (2003) Altered excitability of motor neurons in a transgenic mouse model of familial amyotrophic lateral sclerosis. Neurosci Lett 351: 153-156. CrossRef Medline

Pun S, Santos AF, Saxena S, Xu L, Caroni P (2006) Selective vulnerability and pruning of phasic motoneuron axons in motoneuron disease alleviated by CNTF. Nat Neurosci 9:408-419. CrossRef Medline

Reddy LV, Koirala S, Sugiura Y, Herrera AA, Ko CP (2003) Glial cells maintain synaptic structure and function and promote development of the neuromuscular junction in vivo. Neuron 40:563-580. CrossRef Medline

Reist NE, Smith SJ (1992) Neurally evoked calcium transients in terminal Schwann cells at the neuromuscular junction. Proc Natl Acad Sci U S A 89:7625-7629. CrossRef Medline

Reynolds ML, Woolf CJ (1992) Terminal Schwann cells elaborate extensive processes following denervation of the motor endplate. J Neurocytol 21: 50-66. CrossRef Medline

Robitaille R (1998) Modulation of synaptic efficacy and synaptic depression by glial cells at the frog neuromuscular junction. Neuron 21:847-855. CrossRef Medline

Rocha MC, Pousinha PA, Correia AM, Sebastião AM, Ribeiro JA (2013) Early changes of neuromuscular transmission in the SOD1(G93A) mice model of ALS start long before motor symptoms onset. PLoS One 8:e73846. CrossRef Medline

Rochon D, Rousse I, Robitaille R (2001) Synapse-glia interactions at the mammalian neuromuscular junction. J Neurosci 21:3819-3829. Medline

Rousse I, St-Amour A, Darabid H, Robitaille R (2010) Synapse-glia interactions are governed by synaptic and intrinsic glial properties. Neuroscience 167:621-632. CrossRef Medline

Saxena S, Roselli F, Singh K, Leptien K, Julien JP, Gros-Louis F, Caroni P (2013) Neuroprotection through excitability and mTOR required in ALS motoneurons to delay disease and extend survival. Neuron 80:80-96. CrossRef Medline

Schaefer AM, Sanes JR, Lichtman JW (2005) A compensatory subpopulation of motor neurons in a mouse model of amyotrophic lateral sclerosis. J Comp Neurol 490:209-219. CrossRef Medline

Siklós L, Engelhardt J, Harati Y, Smith RG, Joó F, Appel SH (1996) Ultrastructural evidence for altered calcium in motor nerve terminals in amyotropic lateral sclerosis. Ann Neurol 39:203-216. CrossRef Medline

Son YJ, Trachtenberg JT, Thompson WJ (1996) Schwann cells induce and guide sprouting and reinnervation of neuromuscular junctions. Trends Neurosci 19:280-285. CrossRef Medline

Todd KJ, Auld DS, Robitaille R (2007) Neurotrophins modulate neuronglia interactions at a vertebrate synapse. Eur J Neurosci 25:1287-1296. CrossRef Medline

Todd KJ, Darabid H, Robitaille R (2010) Perisynaptic glia discriminate patterns of motor nerve activity and influence plasticity at the neuromuscular junction. J Neurosci 30:11870-11882. CrossRef Medline

Turner BJ, Ackerley S, Davies KE, Talbot K (2010) Dismutase-competent SOD1 mutant accumulation in myelinating Schwann cells is not detrimental to normal or transgenic ALS model mice. Hum Mol Genet 19: 815-824. CrossRef Medline

Uchitel OD, Appel SH, Crawford F, Sczcupak L (1988) Immunoglobulins from amyotrophic lateral sclerosis patients enhance spontaneous transmitter release from motor-nerve terminals. Proc Natl Acad Sci U S A 85:7371-7374. CrossRef Medline

Valdez G, Tapia JC, Lichtman JW, Fox MA, Sanes JR (2012) Shared resistance to aging and ALS in neuromuscular junctions of specific muscles. PLoS One 7:e34640. CrossRef Medline

Wang L, Gutmann DH, Roos RP (2011) Astrocyte loss of mutant SOD1 delays ALS disease onset and progression in G85R transgenic mice. Hum Mol Genet 20:286-293. CrossRef Medline

Wang L, Pytel P, Feltri ML, Wrabetz L, Roos RP (2012) Selective knockdown of mutant SOD1 in Schwann cells ameliorates disease in G85R mutant SOD1 transgenic mice. Neurobiol Dis 48:52-57. CrossRef Medline

Wong PC, Pardo CA, Borchelt DR, Lee MK, Copeland NG, Jenkins NA, Sisodia SS, Cleveland DW, Price DL (1995) An adverse property of a familial ALS-linked SOD1 mutation causes motor neuron disease characterized by vacuolar degeneration of mitochondria. Neuron 14:1105-1116. CrossRef Medline

Wright MC, Potluri S, Wang X, Dentcheva E, Gautam D, Tessler A, Wess J, Rich MM, Son YJ (2009) Distinct muscarinic acetylcholine receptor subtypes contribute to stability and growth, but not compensatory plasticity, of neuromuscular synapses. J Neurosci 29:14942-14955. CrossRef Medline

Yamanaka K, Chun SJ, Boillée S, Fujimori-Tonou N, Yamashita H, Gutmann DH, Takahashi R, Misawa H, Cleveland DW (2008) Astrocytes as determinants of disease progression in inherited amyotrophic lateral sclerosis. Nat Neurosci 11:251-253. CrossRef Medline

Zardini DM, Parry DJ (1994) Identification, distribution, and myosin subunit composition of Type IIX fibers in mouse muscles. Muscle Nerve 17:1308-1316. CrossRef Medline 